\title{
1 Sequence of proteome profiles in preclinical and symptomatic Alzheimer's
} 2 disease

3

4

Xiaohang Li $^{1,2} \underline{\text { ORCID 0000-0002-7316-2196 }}$, Konstantinos C. Tsolis ${ }^{3}$, Marta J. Koper ${ }^{1,2,4,5}$, Alicja Ronisz $^{1,2} \underline{\text { ORCID 0000-0002-4310-0445 }}$, Simona Ospitalieri ${ }^{1,2}$, Christine A.F. von Arnim ${ }^{6,7}$ ORCID 0000-0002$\underline{\text { 8614-2223 }}$, Rik Vandenberghe ${ }^{8,9} \underline{\text { ORCID 0000-0001-6237-2502 }}$, Thomas Tousseyn ${ }^{10}$, Angelika Scheuerle $^{11}$, Anastassios Economou ${ }^{3}$ ORCID 0000-0002-1770-507X, Sebastien Carpentier ${ }^{12}$ ORCID 0000-0002-7389-6405, Markus Otto ${ }^{6}$, Dietmar Rudolf Thal ${ }^{1,2,10} \underline{\text { ORCID 0000-0002-1036-1075 }}$

1 Laboratory for Neuropathology, Department of Imaging and Pathology, KU Leuven (University of Leuven), Leuven, Belgium.

${ }^{2}$ Leuven Brain Institute (LBI), KU Leuven (University of Leuven), Leuven, Belgium.

${ }^{3}$ Laboratory of Molecular Bacteriology, Rega Institute, Department of Microbiology and Immunology, KU Leuven (University of Leuven), Leuven, Belgium.

${ }^{4}$ Laboratory for the Research of Neurodegenerative Diseases, Department of Neurosciences, KU Leuven (University of Leuven), Leuven, Belgium.

${ }^{5}$ Center for Brain and Disease Research, VIB, Leuven, Belgium.

${ }^{6}$ Department of Neurology, University of Ulm, Ulm, Germany

${ }^{7}$ Department of Geriatrics, University Medical Center Göttingen, Göttingen, Germany

${ }^{8}$ Department of Neurology, UZ Leuven (University Hospitals Leuven), Leuven, Belgium

${ }^{9}$ Laboratory for Cognitive Neurology, Department of Neurosciences, KU Leuven (University of Leuven), Leuven, Belgium

${ }^{10}$ Department of Pathology, UZ Leuven (University Hospitals Leuven), Leuven, Belgium

${ }^{11}$ Institute of Pathology, University of Ulm, Ulm, Germany

${ }^{12}$ BIOMED facility for SYstems BIOlogy based MAss spectrometry, KU Leuven (University of Leuven), Leuven, Belgium 
1 Corresponding author:

2 Dietmar R. Thal, Department of Imaging and Pathology, KU Leuven, Herestraat 49, 3000

3 Leuven, Belgium; E-Mail: Dietmar.Thal@kuleuven.be; Tel.: +32-16-3-44047

4

\section{Conflict of interest statement}

6 CAFvA received honoraria from serving on the scientific advisory board of Roche (2018-19)

7 and Dr. Willmar Schwabe GmbH \&Co. KG (2019) and has received funding for travel and

8 speaker honoraria from Nutricia GmbH (2014-15), Lilly Deutschland GmbH (2013-2016),

9 Biogen (2016-2018), Roche (2017-2018) and Dr. Willmar Schwabe GmbH \&Co. KG (2014-

10 2015). RV's institution has consultancy agreements (RV as PI) with AC Immune, material

11 transfer agreements with Avid Radiopharmaceuticals, and clinical trial agreements with

12 AbbVie, Biogen, Novartis and Roche. MO gave scientific advice for Roche, Biogen, Fujirebio

13 and Axon neurosciences. DRT received speaker honorarium from Novartis Pharma Basel

14 (Switzerland) and Biogen (USA), travel reimbursement from GE-Healthcare (UK), and UCB

15 (Belgium), and collaborated with GE-Healthcare (UK), Novartis Pharma Basel (Switzerland),

16 Probiodrug (Germany), and Janssen Pharmaceutical Companies (Belgium).

17

18

19 


\section{Abstract}

2 Proteome profile changes in Alzheimer's disease (AD) brains have been reported. However, it

3 is unclear whether they represent a continuous process, or whether there is a sequential

4 involvement of distinct proteins. To address this question we used mass spectrometry. We

5 analyzed soluble, dispersible, SDS, and formic acid fractions of neocortex homogenates

6 (mainly Brodmann area 17-19) from 18 pathologically-diagnosed preclinical AD, 17

7 symptomatic $\mathrm{AD}$, and 18 cases without signs of neurodegeneration. By doing so, we identified

8 four groups of AD-related proteins being changed in levels in preclinical and symptomatic AD

9 cases: early-responding, late-responding, gradually-changing and fraction-shifting proteins.

10 Gene ontology analysis of these proteins and all known AD-risk/causative genes identified

11 vesicle endocytosis and the secretory pathway-related processes as an early-involved AD

12 component. In conclusion, our findings suggest that subtle changes involving the secretory

13 pathway and endocytosis precede severe proteome changes in symptomatic AD as part of the

14 preclinical phase of $\mathrm{AD}$. The respective early-responding proteins may also contribute to

15 synaptic vesicle cycle alterations in symptomatic AD.

\section{Key Words}

18 Pathologically-diagnosed preclinical Alzheimer's disease, symptomatic Alzheimer's disease,

19 amyloid $\beta$-peptide, proteomics, label-free LC-MS/MS, human neocortex 


\section{Narrative}

\subsection{Contextual background}

Alzheimer's disease (AD) is the most frequent neurodegenerative disorder [1]. Its pathological hallmark lesions are extracellular amyloid plaques containing amyloid $\beta$-protein $(\mathrm{A} \beta)$ and intracellular neurofibrillary tangles (NFTs) that consist of hyperphosphorylated tau protein (ptau) [2-4]. A $\beta$ plaques and NFTs are not only found in symptomatic AD (symAD) patients, but also in non-demented individuals, with a less widespread distribution, indicative of the preclinical stage of the disease $[5,6]$. The expansion patterns of $A \beta$ plaque and NFT pathology follow distinct sequences in which the different brain regions become hierarchically involved. These sequences are described by the phases of $A \beta$ deposition [6] and the Braak NFT-stages [7], and differ from one another. Neocortical brain regions, including frontal, parietal, and occipital cortex develop $A \beta$ plaques in non-demented individuals long before NFT develop. In contrast, NFTs occur first in another brain region, the transentorhinal cortex, in non-demented individuals while $\mathrm{A} \beta$ plaques are completely absent or are restricted to the neocortex $[6,8]$. Accordingly, neocortical brain regions offer the possibility to study A $\beta$ plaque-induced changes in the absence of local NFTs in non-demented individuals. In symAD, both $\mathrm{A} \beta$ plaques and NFTs are prevalent and indicate the full-blown damage of the neocortex in AD.

To date, non-demented individuals with $\mathrm{A} \beta$ plaque pathology are considered to exhibit $\mathrm{AD}$ neuropathological changes [9]. Therefore, they can be classified as pathologically-diagnosed preclinical $\mathrm{AD}$ (p-preAD) cases [5]. Individuals without $\mathrm{A} \beta$ plaques are classified as nonAD cases regardless of the absence or presence of NFTs. On the other hand, NFTs can occur independent of $\mathrm{A} \beta$ plaques in the brains of aged, cognitively normal and impaired individuals. This phenomenon is referred to as primary age-related tauopathy (PART) [10]. However, PART does by definition not affect the frontal or occipital cortex. Accordingly, frontal/occipital cortex is ideally suited for studying proteome changes in $\mathrm{AD}$ without interference of PART. 
1 The development of $\mathrm{A} \beta$ plaques and NFTs in the AD brain coincides with overall proteome

2 changes [11-17]. However, these studies either defined asymptomatic AD as non-demented

3 individuals with moderate-severe NFT pathology and neuritic plaque pathology or did not

4 include such cases, whereas cases with initial A $\beta$ plaque and NFT pathology were considered as non $\mathrm{AD}$ controls. Thus, it remains still unclear whether initial proteome changes can be observed in p-preAD cases and if they differ from those in the symptomatic stage of AD.

7 Distinct intracellular and extracellular forms of $A \beta$ aggregates exist, including soluble $A \beta$ 8 oligomers, dispersible $\mathrm{A} \beta$ oligomers, protofibrils and fibrils, membrane-associated (sodium 9 dodecyl sulfate (SDS)-soluble) A $\beta$ aggregates, and plaque-associated (formic acid (FA)soluble) A $\beta$ fibrils [18-24]. In addition, changes in the subcellular topology of several proteins

11 have been described with the progression of neurodegeneration [25-27]. However, in published proteomic studies on $\mathrm{AD}$, brain homogenates were prepared with detergent-containing buffers 13 [12-16]. As a result, information about changes in the solubility of proteins during AD progression which implies their subcellular topology or aggregation status is missing. In an earlier publication [5], we reported a fractionation method of human brain homogenates, which allows separation of proteins based on differences in their solubility. This fractionation method 17 yields four fractions, including 1. a soluble fraction (which contains soluble proteins), 2. a 18 dispersible fraction (which contains insoluble proteins that are in mixture with the intra- or extracellular fluid and endosomes, exosomes, and synaptosomes), 3. a detergent-soluble sodium dodecylsulfate (SDS) fraction (which contains SDS-soluble, larger organelles and membrane structures-associated proteins), and 4. a formic acid (FA) fraction (which contains highly insoluble, aggregated proteins). Although detergent-soluble (presumably membraneassociated) proteins $[13,14]$, plaques and NFT isolated by laser-capture microdissection were analyzed $[11,28]$, there is a gap of knowledge related to proteins of the soluble and dispersible fractions and their contribution, especially to the initial steps of AD pathogenesis. 


\subsection{Study conclusions and disease implications}

3 To the best of our knowledge, the analyzed neocortex samples cover all steps in the evolution

4 of AD pathology. Therefore, our results substantially extend the understanding of proteome changes in $\mathrm{AD}$ by showing four groups of $\mathrm{AD}$-related proteins in neocortex homogenates: 1.

6 early-responding proteins that exhibited changed levels in p-preAD compared to nonAD 7 controls, 2. late-responding proteins with changed levels in symAD compared to p-preAD, 3. 8 gradually-changing proteins with level changes increasing or decreasing linearly with AD 9 development from nonAD to symAD; and 4. fraction-shifting proteins that shifted from more into less soluble fractions in symAD. The sequential occurrence of the protein level changes in

11 the neocortex allows the distinction of three stages (Figure 1): stage $0=$ no AD-related changes; stage $1=$ changes exclusively in early-responding proteins in p-preAD cases; stage $2=$ changes

13 in protein levels of late-responding, gradually-changing and fraction-shifting proteins in symAD cases, indicating serious alterations of the brain parenchyma and presumably explaining dysfunction of the AD cortex.

By using fractions of the brain lysates, we were able to find a specific and early decrease of 17 proteins that were mainly seen in the dispersible fraction containing endo-, exo-, and synaptosomes. Among the four identified early-responding proteins, two were known to be not only involved in the clathrin-coated endocytic vesicle membrane, but were also related to lysosomes and Golgi-associated vesicle generation. The reduction of these proteins in p-preAD

21 and symAD cases points to problems in the intracellular transport mechanisms as an early and probably disease-driving pathogenetic event in AD. This hypothesis is supported by our finding that more proteins related to these pathways became involved in symAD. Furthermore, the synaptic vesicle cycle was over-represented by the proteins that were indicated by different statistical approaches for their association with AD progression. 
1 These findings provide complementary insights to previous neocortex-focused proteomics

2 studies. When comparing the list of proteins exhibiting level changes during the development

3 of AD pathology with those from other published proteomic studies using human postmortem

4 brain tissues [12, 13, 15-17, 29-34], we confirmed $43 / 50$ proteins with changed levels in AD

5 pathogenesis. We found seven proteins that were not yet described to show changed levels in 6 AD.

7 As with all cross-sectional studies analyzing post-mortem brain samples, it is important to keep

8 in mind that we only look at one point in time in a given individual and cannot draw direct

9 conclusions regarding the functional meaning of our findings. However, $A \beta$ and $p$-tau pathology in transgenic animals also show a hierarchical involvement of different brain regions

11 in the process of developing full-blown $A \beta$ or p-tau pathology [35, 36]. This argues in favor of 12 the hypothesis that a similar sequential involvement of brain regions in human AD is indicative 13 for a development of these pathologies over time. This hypothesis is supported by follow-up studies using $\mathrm{A} \beta$ or tau-PET to monitor $\mathrm{AD}$ progression in patients [37-39]. However, resilience factors may be active in $\mathrm{p}$-preAD cases and protect them from further progression. Our findings of some proteins that change in abundance in p-preAD and return the control levels in symAD (e.g. RL31_HUMAN, CALM1_HUMAN) may support the presence of possible resilience 18 phenomena in p-preAD.

19 The differences between the nonAD control, p-preAD, and symAD cases in their mean age represent another limitation of autopsy studies for $\mathrm{AD}$ because of the increase of this pathology with age $[8,40]$. However, statistical analysis was controlled for age and sex to avoid the respective bias in our results. Moreover, it must be kept in mind that our conclusions are based on one brain region, i.e. the neocortex where $A \beta$ deposition precedes $p$-tau pathology $[6,7]$. In other brain regions, where $p$-tau pathology precedes $A \beta$ deposition the changes in protein expression especially in p-preAD cases may vary from those observed here. The number of 
1 cases studied here $(n=53)$ is in the range of other mass spectrometry studies [16, 29, 41]. Due

2 to differences in the technical details of our protocols for preparing and measuring the samples

3 for mass spectrometry and a very conservative statistical analysis strategy compared to other

4 studies (details in Suppl. Methods and Discussion), we identified less proteins but were able to

5 identify the early involvement of vesicle endocytosis and the secretory pathway-related

6 processes in the pathogenesis of AD. The separate analysis of four biochemical fractions of

7 neocortex homogenates allowed the detection of protein abundance changes in specific groups

8 of proteins based upon their solubility and their occurrence in vesicles or larger organelles and

9 protein aggregates. The observed shifts of protein abundance from more soluble fractions into less soluble fractions as shown here in symAD cases indicate substantial loss of soluble or

11 dispersible/vesicle-associated proteins that accumulate instead in larger organelles and/or 12 protein aggregates probably impairing their functional availability. Such changes were not 13 reported by studies without performing prior fractionation [12].

14 Previous mass spectrometry studies identified mainly protein pathways related to the activation 15 of astrocytes, i.e. astrogliosis, and microglial cells, i.e. microgliosis, as well as to 16 neurodegenerative events, especially the loss of synaptic markers [12]. Our finding of a 17 decrease of synaptic vesicle cycle-related proteins confirms the loss of synaptic proteins. 18 Although astro- and microglial activation-related protein abundance changes were not as 19 evident as in other studies, the increase of vimentin (a protein that is expressed in activated astrocytes [42] and various other cell types of mesenchymal origin, including endothelial cells

21 [43]) and the glial excitatory amino acid transporter (EAAT2) [44] are in line with an increased expression of astroglial markers. An increase in Triton X-100 insoluble EAAT2 in AD has also 23 been reported by others [45]. However, other groups found unchanged EAAT2 mRNA and 24 protein levels [46], or even decreased protein levels [12] indicating that the EAAT2 results 
1 [47] may contribute to an increased abundance of SDS-soluble EAAT2 as observed here. Major

2 histocompatibility complex (MHC) class II antigen processing and presentation is a process

3 that includes vesicle transport between the immune competent cells [48], and is thus possibly

4 associated with microglia function. It was over-represented by a group of proteins that exhibited decreased levels. Accordingly, it is tempting to speculate that an impaired vesicle transport in AD also alters proper immune response and leads to a consecutive increase of MHC-class IIexpression by microglial cells [49].

8 Given the reduction of proteins involved in cellular and extracellular vesicle transport as early as in p-preAD as observed in this study and given the central role of vesicle transport for the synaptic vesicle cycle, it is tempting to speculate that the alteration of the synaptic vesicle cycle

11 is a very early event in $\mathrm{AD}$ progression, which precedes the manifestation of detectable p-tau pathology in neocortical brain regions. Further arguments in favor of this hypothesis are that 1 .

13 tau is involved in the regulation of axonal transport and abnormal phosphorylation or missorting of tau may occur when the vesicle transportation is altered, 2. mis-sorting of distinct ptau species depending on its phosphorylation sites has recently been described as the initial prerequisite of p-tau pretangle and NFT formation [50], and 3. that endosomal dysfunction can

17 induce synapse loss and tau hyperphosphorylation [51]. Arguments against this hypothesis are

18 1. the presence of p-tau pathology in subcortical brain regions that project into the neocortex, e.g. locus coeruleus, raphe nuclei and neurons of the basal nucleus of Meynert already in PART and p-preAD cases [52-54] and 2. tau-induced alterations of the axonal transport in these neurons explain insufficient vesicle transport $[55,56]$ and probably p-tau mis-sorting. Therefore, subcortical p-tau pathology may contribute at least partially to the reduction of protein abundance of vesicle transport-related proteins. A third alternative is that $A \beta$, which is present in p-preAD neocortex, interacts with membrane proteins that are cargos of clathrin- 
1 protein $\left(\operatorname{PrP}^{\mathrm{C}}\right)$ is one of the proteins that undergoes clathrin-dependent endocytosis [57-59]. It

2 has been shown to bind to $A \beta$ oligomers as well as to p-tau [60-62]. Accordingly, the interaction

3 of $\mathrm{A} \beta$ and/or $\mathrm{p}$-tau with $\operatorname{PrP}^{\mathrm{C}}$ could be crucial for the impairment of clathrin-related vesicle

4 endocytosis and the trafficking of vesicles. An additional argument favoring this hypothesis is

5 our finding that there is a reduction of $\operatorname{PrP}^{\mathrm{C}}$ in symAD compared to non-AD cases. This is in

6 line with previous reports showing a reduced $\mathrm{PrP}^{\mathrm{C}}$ expression in the $\mathrm{AD}$ brain $[61,63,64]$. To

7 clarify which of these hypotheses is true, neuronal cell culture experiments will help to 8 investigate whether induced p-tau pathology in neurons alters the synaptic vesicle cycle in vitro,

9 whether $\mathrm{A} \beta$ can induce synaptic vesicle cycle abnormalities, and whether knocking-down $\operatorname{PrP}^{\mathrm{C}}$ will normalize potential $A \beta$ or $p$-tau induced alterations of the synaptic vesicle cycle. Thus, 11 understanding the role of vesicle transport in $\mathrm{AD}$ will be a critical step to target the disease more efficiently than today.

\section{Consolidated results and study design}

To clarify whether changes in protein abundance occur in a sequential manner by involving step-by-step more and more proteins throughout the pathogenesis of $\mathrm{AD}$, we analyzed neocortex samples from 53 autopsy brains (18 nonAD control (mean age 61 years), 18 p-preAD (mean age 70 years) and 17 symAD cases (mean age 76 years)) neuropathologically and by mass spectrometry.

We determined the topographical distribution of the $\mathrm{AD}$ hallmark lesions, i.e. $\mathrm{A} \beta$ plaques and

21 NFTs, and classified it according to widely accepted staging systems. Phases of A $\beta$ plaque pathology were determined according to Thal et al. [6], NFT stages according to Braak and

23 Braak [7]. In addition, other staging systems and semi-quantitative scores were used to receive 24 global measures for cerebral amyloid angiopathy (CAA) [65, 66], granulovacuolar degeneration (GVD) [67], and neuritic plaques [68] as well as local measures for A $\beta$ plaques, 
1 NFTs, and CAA pathology. We assessed the clinical dementia rating (CDR) [69] scores on

2 the basis of available clinical records.

3 After fractionation of the neocortex homogenates and sample preparation steps, we analyzed

4 the samples using label-free liquid chromatography coupled to tandem mass spectrometry (LCMS/MS). We identified 1449 unique protein regardless of the fraction information after applying exclusion criteria. For statistical analysis we used two independent approaches: a supervised univariate approach and an unsupervised multivariate approach. Protein abundances were compared between nonAD control, p-preAD, and symAD cases using a univariate approach. Controlling for age and sex or post-mortem interval (PMI), i.e. the time between death and autopsy, in regression models allowed us to determine disease-related changes that

11 are independent from age, sex or PMI. Four proteins were changed in p-preAD cases compared to nonAD and considered as "early-responding proteins". Twenty-six proteins exhibited abundance changes between p-preAD and symAD cases and were termed "late-responding proteins". As "gradually-changing proteins" showing a linear increase or decrease in the development from nonAD to symAD 20 additional proteins were identified that were not included in the early- or late-responding proteins. We also identified five proteins that showed reduced abundance in the soluble or dispersible fraction accompanied by an increase in the SDS fraction, when we compared symAD cases with non $\mathrm{AD}+$ p-preAD cases. They were referred to as fraction-shifting proteins.

To investigate the functional impact of the early-responding, late-responding, gradually21 changing and fraction-shifting proteins, as well as of their changes in AD, we computed their over-represented functional attributes using gene ontology (GO) terms, i.e. terms that link 23 attributes, including functional attributes to genes and its products. Two early-responding 24 proteins as well as five gradually-changing proteins were involved in vesicle endocytosis, secretory pathways and/or the synaptic vesicle cycle whereas late-responding proteins included 
1 proteins covering a large range of cellular functions. The proteins associated with vesicle

2 endocytosis, secretory pathway and/or the synaptic vesicle cycle were mostly exhibited in the

3 neuropil and/or located in vesicles based on ultrastructural information [70].

4 To identify functional protein networks altered in AD we employed the STRING Database.

5 Vesicle transport/endocytosis and secretory pathway involved proteins formed a cluster in

6 addition to two other clusters including either $A \beta /$ amyloid precursor protein (APP) or tau.

7 Comparison and fusion of the network established on the basis of the proteins exhibiting

8 significant abundance changes in this study with the network considering all known Alzheimer-

9 related genes [71, 72] showed that vesicle endocytosis, secretory pathway, and synaptic vesicle

cycle proteins formed a third cluster in addition to the two clusters that included either A $\beta / A P P$

11 or tau and were already evident when restricting the network analysis to the known Alzheimer

12 genes.

13 To clarify the relationship between the protein abundances and the neuropathological AD 14 parameters assessed in this study, we correlated the neuropathological parameters with 1. the protein abundances of early-, late-responding, and gradually-changing proteins using a univariate approach and 2. protein abundances of all identified proteins in a multivariate setting.

17 Changes in early-responding proteins were best correlated with the local presence of $\mathrm{A} \beta$ 18 whereas late-responding proteins and gradually-changing proteins correlated best with 19 parameters describing the disease progression. Vesicle endocytosis and secretory pathwayrelated proteins clustered in this analysis. When using unsupervised multivariate weighted

21 correlation network analysis (WGCNA) including all identified proteins, we found three modules covering 1 . vesicle- and synapse-related proteins, 2. cytoskeleton-related proteins and

23 3. extracellular matrix and cell membrane-related proteins. After excluding all proteins that 24 showed an association with age or sex, vesicle-mediated transport, clathrin-coated endocytic vesicles, negative regulation of apoptosis and caspase-mediated cleavage of cytoplasmic 
1 proteins were still associated with the progression of the AD-related neuropathological 2 parameters.

3

4

\section{Detailed Results}

\subsection{Identification of proteins showing level changes during the pathogenesis of $A D$}

We neuropathologically characterized 18 control cases without AD pathology (nonAD), 18 ppreAD and 17 symAD cases (Table S1). Soluble, dispersible, SDS, and FA fractions from occipital (Brodmann areas 17-19) or frontal (Brodmann area 6) neocortex homogenates of all cases were analyzed using label-free LC-MS/MS (Figure 2a, Table S2, Suppl. Methods). The two nonAD cases, for which only frontal cortex tissue (Brodmann area 6) was available, did not show a different protein expression pattern from occipital cortex samples from nonAD in a unweighted sample clustering analysis (Figure S1) and were, therefore, accepted as nonAD neocortex tissue. Proteome changes involved in p-preAD and symAD were determined by integrated analyses that combined quantitative proteomics, detailed neuropathological examination, regression analysis, clustering, and gene ontology over-representation tests (Suppl. Methods). Among the 1449 unique proteins (regardless of fraction) that were identified after applying the exclusion criteria (Suppl. Methods), 53 (regardless of fraction) showed changes in abundance among non $\mathrm{AD}$, p-pre $\mathrm{AD}$ and symAD cases using a supervised univariate statistical approach (Kruskal-Wallis $\mathrm{H}$ test with multiple comparisons of mean ranks for all groups, $\mathrm{p}<0.05$ ) (Figure S2, Table S3). Their immunohistochemical distribution pattern in the normal human cerebral cortex is provided in Table S3 (Suppl. Methods). These proteins were then analyzed by regression models controlled for age and sex, and the changes detected in 49 proteins (regardless of fraction) remained significant (Figure S3a). Four proteins, referred to as early-responding proteins, showed significantly changed levels between the nonAD and ppreAD cases (Figure $2 \mathrm{~b}$ and Figure $\mathrm{S} 2$ ). Twenty-six proteins, considered as late-responding 
1 proteins, showed changes in abundance between p-preAD and symAD (Figure $2 b$ and Figure

2 S2). One of them, RL31_HUMAN was also classified as early-responding protein. Moreover,

3 the abundance of 24 proteins (regardless of fraction) gradually changed from nonAD to symAD

4 cases (Figure $2 \mathrm{~b}$ and Figure S2). Among them, 20 proteins (regardless of fraction), which were not included in the early- or late-responding proteins, were referred to as gradually-changing proteins (Figure $2 \mathrm{~b}$ and Figure $\mathrm{S} 2$ ). To determine the statistical robustness of our analysis, we performed a post-hoc power analysis on the abundance of the early-, late-responding and gradually-changing proteins, regarding the difference among the three groups. Most of them showed a power of $100 \%$ (Figure S3a).

One early-responding protein (endophilin-A1 (SH3G2_HUMAN)) and three late-responding 11 proteins (including the AD hallmark proteins, i.e. APP (A4_HUMAN) and tau (TAU_HUMAN), as well as ubiquitin carboxyl-terminal hydrolase isozyme L1 (UCH-L1, UCHL1_HUMAN)) also exhibited changes in their levels between nonAD and symAD cases. The findings were confirmed by regression analysis controlled for PMI (Figure S3b, S3c). Early-responding proteins were most abundant in the dispersible fraction, which contains insoluble protein oligomers and small vesicles, including endo-, exo-, and synaptosome. Only one protein from SDS fraction, calmodulin-1, increased in abundance in this early stage of AD. On the contrary, in symAD, protein changes were detected in all neocortical fractions, and included aggregation of FA-soluble APP/A $\beta$ and prion protein (PRIO_HUMAN), indicating extensive and substantial changes of the brain parenchyma (Fig. 2b, Fig. S2). Among the early-, late-responding and gradually-changing proteins, UCH-L1 and plectin (PLEC_HUMAN) showed reduced abundance in the soluble fraction accompanied by an increase in the SDS fraction (Figure 2b-c, Table S4). To identify all proteins exhibiting a similar shift in subcellular topology or in its aggregation status, we compared symAD cases with the group of p-preAD+nonAD cases as well as nonAD cases with the group of p-preAD+symAD 
1 cases. In doing so, three other proteins $[73,74]$ were identified as fraction-shifting proteins,

2 including Secernin-1 [75], which showed a reduction in its abundance in the dispersible fraction

3 (Figure 2c, Table S4). One of the fraction-shifting proteins, phytanoyl-CoA hydroxylase-

4 interacting protein-like (PHIPL_HUMAN) [76], was not identified as an early-, late-responding

5 or gradually-changing protein due to the correction for multiple testing when analyzing nonAD,

6 p-preAD and symAD as three separate groups.

7 Early-responding, late-responding, gradually-changing and fraction-shifting proteins together 8 were referred to as AD-related proteins (Figure 2a).

9 Single proteins exhibited opposite trends when comparing nonAD and p-preAD as well as ppreAD and symAD. However, no significant differences occurred between nonAD and symAD

11 cases. For example, RL31_HUMAN, showed a significant decrease in p-preAD and an increase 12 towards normal levels in symAD. UBA1_HUMAN, CBR1_HUMAN, and TAGL3_HUMAN 13 levels decreased significantly from p-preAD to symAD whereas an upward trend was observed 14 between nonAD and p-preAD cases.

3.2 Gene ontology over-representation and network analysis identified vesicle endocytosis and the secretory pathway-related processes as early changed functions in p-preAD

18 Gene Ontology (GO) information provides a summary of the current scientific knowledge about the attributes of genes and their products. To identify the most relevant biological functions represented by the three sequential classes of proteins, we performed a GO over-representation

21 analysis. We took the tissue specificity and the nature of the proteomics data into account by including all proteins that were identified in the neocortex samples in this study as specific

23 background for the gene ontology evaluation (Suppl. Methods). In early-responding proteins, 24 "clathrin-coated endocytic vesicle membrane" (GO: 0030669) and the secretory pathway (R- 
1 Vesicle Biogenesis") were over-represented, whereas abundance changes in late-responding

2 proteins extended to "cytoplasm" (GO: 0005737) and were associated with pathways including

3 “caspase-mediated cleavage of cytoskeletal proteins" (R-HSA-264870) (Table S5a). Gradually-

4 changing proteins were not only associated with the same pathways as the early-responding

5 proteins, but also with other biological processes related to clathrin and the AP2 adaptor

6 complex, e.g., "synaptic vesicle cycle" (KEGG: hsa04721) (Table S5a). In addition to these

7 pathways, GO over-representation analysis also revealed possible proteome changes in "MHC

8 class II antigen presentation" (GO: 0019886 and R-HSA-2132295) and "neurodegeneration"

9 (Table S5a).

AD causative genes (APP, PSEN1and PSEN2) as well as AD risk genes were published in the

11 past decades $[71,72,77-81]$. The respective genes are here referred to as AD-related genes. To

12 provide a more comprehensive view on the processes involved in AD pathogenesis and to

13 clarify the relation between the AD-related proteins and genes, we performed a protein-protein 14 interaction network analysis using the STRING Database [82] (Suppl. Methods). The confidence (cutoff: 0.7) of a functional and/or physical protein-protein interaction was computed based on active interaction sources including experimental data and curated

17 databases (Suppl. Methods). Among AD-related genes, two networks were identified (Figure 18 3a), including APP-metabolism-related and endocytosis-related gene clusters. Among the four 19 groups of AD-related proteins identified in this study, one network with APP/A $\beta$, tau, and vesicle endocytosis/the secretory pathway-related clusters was observed (Figure 3b). When we

21 analyzed the AD-related proteins and the known AD-related genes together, we identified a 22 large network with 32 vesicle-mediated transport (GO: 0016192)-related proteins/genes as the 23 backbone. Here, we observed a cluster containing vesicle endocytosis/the secretory pathway24 related proteins/genes in addition to $\mathrm{A} \beta$-centered and tau-related clusters (Figure $3 \mathrm{c}$ ). Some of 
1 the AD risk genes such as TREM2 were not strongly linked to the AD-related proteins (Figure $23 \mathrm{c})$

3

4

\subsection{Association between the AD-related protein level changes and AD progression}

To identify the proteins that are associated with distinct aspects of AD pathology, we performed hierarchical clustering of the p-values indicating the significance of the association and the correlation coefficients describing the strength of the association between respective protein levels of the early-, late-responding and gradually-changing proteins and the AD-related neuropathological parameters (Figure 4a-b and Table S6). Three out of four early-responding proteins (SH3G2_HUMAN, AP1B1_HUMAN, and CALM1_HUMAN) showed significant associations ( $\mathrm{p}<0.05$, partial correlation, controlled for age and sex) with the presence of $\mathrm{A} \beta$ plaques in the occipital cortex (Figure 4a and Table S6). Among them, SH3G2_HUMAN exhibited a moderate negative correlation with this measurement (Figure $4 \mathrm{~b}$ and Table S6). Such an association with the presence/absence of $A \beta$ plaques was less obvious for the majority of late-responding or gradually-changing proteins (Figure 4a and Table S6). On the contrary, associations were seen between the majority of late-responding or gradually-changing proteins and $\mathrm{A} \beta$ phase, Braak NFT-stage, $\mathrm{A} \beta$ load, p-tau density, CERAD, NIA-AA degree of AD pathology, and GVD-stage (Figure 4a and Table S6). Cerebral amyloid angiopathy (CAA) stage and severity negatively correlated with the levels of one early-responding proteins (SH3G2_HUMAN) (Figure 4b and Table S6).

Moreover, VIME_HUMAN that is expressed by reactive astrocytes moderately correlated with all AD-related parameters that described the evolution of the pathology except for the occipital presence of $\mathrm{A} \beta$ plaques and the occipital CAA severity (Figure $4 \mathrm{~b}$ and Table S6). FIBG_HUMAN exhibited an association with the overall and occipital CAA severity $(\mathrm{p}<$ 0.001, partial correlation, controlled for age and sex; correlation coefficient: 0.5 ) and with the 
1 CAA stage $(\mathrm{p}<0.05$, partial correlation, controlled for age and sex; correlation coefficient:

$20.353)$ (Figure 4a-b and Table S6).

3 The comparison of the neuropathological parameters among nonAD, p-preAD, and symAD

4 cases showed the expected development of the disease (Figure 4c). Two nonAD and two p5 preAD cases exhibited p-tau lesions in the occipital cortex (Figure 4c). Three of these cases 6 (case Nos. Ctrl3, Ctrl6, p-preAD2) showed few threads, pretangles and/or astrocytes 7 presumably related to a very mild, probably clinically unapparent, chronic traumatic injury. The 8 fourth case (case No. p-preAD12) exhibited threads and neuritic plaques compatible with Braak $9 \quad$ NFT-stage III (Table S1).

\subsection{Weighted correlation network analysis (WGCNA)}

12 To confirm and extend our findings with an unsupervised statistical method, we performed a 13 multivariate analysis with the WGCNA algorithm [83] (Suppl. Methods). This algorithm indicated the identified protein modules by colors which were illustrated in the module-trait relationship table (Figure S4a and Table S7). All protein modules that showed a correlation with distinct AD pathology-related parameters in WGCNA were referred to as AD-related modules. Here, three modules, "grey", "pink" and "salmon", were identified as AD-related modules. No evident correlation with age or sex was observed (Figure S4a). Among the modules, both the "grey" (308 proteins regardless of fraction) and the "pink" (72 proteins regardless of fraction) module correlated with the progression from nonAD to symAD cases (Figure S4a). "Grey” proteins also correlated strongly with all AD pathological scores, except the occipital A $\beta$ presence. "Pink" proteins correlated significantly with A $\beta$ phase. Interestingly, the module "salmon" (53 proteins regardless of fraction) did not correlate with the progression from non $\mathrm{AD}$ to symAD, but with the occipital $\mathrm{A} \beta$ plaque load, global CAA-severity, Braak 
1 stage (Figure S4a). When we compared the list of AD-related proteins identified by univariate

2 analysis with the proteins of the "grey", "pink" and "salmon" modules, 16 were found among

3 "grey" proteins, four among "pink" and six among "salmon". Regardless of the fraction

4 information, the number of proteins identified by WGCNA as relevant in AD increased to 41/50 AD-related proteins. The ontologies of the proteins in modules "grey", "pink" and "salmon" were enriched in vesicle and synapse-related (grey), cytoskeleton-related (pink), and extracellular matrix and cell membrane-related (salmon) structural components or biological processes (Table S5b). An overlap of over-represented GO terms among AD-related proteins and modules was observed (Figure S4b). This included 11 GO terms, for example, "synaptic vesicle cycle" (KEGG: hsa04721) and "MHC class II antigen presentation" (R-HSA-2132295).

11 However, as the number of proteins in the "grey", "pink" and "salmon" modules was much larger than that of the AD-related proteins, over-represented GO terms from "grey", "pink" and "salmon" modules covered a large range of pathways or biological functions than our ADrelated proteins (Table S5b), including cell cycle-related pathways, e.g. "recruitment of mitotic centrosome proteins and complexes" (R-HSA-380270).

To determine proteins that changed between nonAD control, p-preAD and symAD cases

17 without collinearity with age and/or sex, we excluded proteins of which the abundances were 18 associated with age and/or sex in linear regression models (Suppl. Methods). WGCNA analysis of these pre-filtered data generated 19 modules (Figure S5a and Table S8). Two protein modules, "grey" and "grey60" were identified as additional AD-related modules and showed 21 significant association with Braak NFT-stage, NIA-AA degree of AD pathology, occipital ptau presence and density scores (Figure S5a). The module "grey60" exhibited additional strong correlations with the occipital A $\beta$ plaque load and the GVD stage (Figure S5a). There were 281

24 proteins regardless of the biochemical fraction in module "grey" and 48 in module "grey60".

25 Fourteen proteins of the "grey" and four of the "grey60" module were contained in our list of 
1 AD-related proteins. GO over-representation analysis identified 13 over-represented GO terms

2 that were also identified on the basis of the AD-related proteins, including "vesicle-mediated

3 transport" (GO: 0016192), "clathrin-coated endocytic vesicle membrane" (GO: 0030669),

4 "negative regulation of apoptotic process" (GO: 0043066), and "caspase-mediated cleavage of cytoskeletal proteins" (R-HSA-264870) (Figure S5b and Table S5c).

Detailed methods and additional detailed discussion are provided in the supporting information.

Acknowledgements: The authors thank Petra Weckx, Kusay Arat, Mohamed Belal Hamed by Fonds Wetenschappelijk Onderzoek Vlaanderen (FWO G0F8516N, G065721N (DRT)), Vlaamse Impulsfinanciering voor Netwerken voor Dementie-onderzoek (IWT 135043 (RV, DRT)), RUN (\#RUN/16/001 KU Leuven (AE)); C1 (FOscil; KU Leuven (AE)) and DIP-BiD (\#AKUL/15/40 - G0H2116N; Hercules/FWO (AE and SC)). MO was supported by EU Joint Programme-Neurodegenerative BiomarkAPD (01ED1203F) and PreFrontAls (01ED1512), the German Federal Ministry of Education and Research (FTLDc 01GI1007A, the German Research Foundation/DFG (SFB1279)).

Author Contributions: XL: study design, biochemistry, mass spectrometry, immunohistochemistry, bioinformatics, statistical analysis, manuscript preparation; KCT: mass spectrometry, critical review of the manuscript; MJK, immunohistochemistry, critical review of the manuscript; AR: immunohistochemistry, neuropathology, critical review of the manuscript; SO: immunohistochemistry, critical review of the manuscript: CAFvA: clinical neurology, critical review of the manuscript; RV: clinical neurology, critical review of the manuscript; TT: neuropathology, critical review of the manuscript; AS: neuropathology, critical 
1 review of the manuscript; AE:, additional study design, critical review of the manuscript; SC:

2 supervision on mass spectrometry and bioinformatics, critical review of the manuscript; MO:

3 clinical neurology, study design, critical review of the manuscript; DRT: study design, project

4 supervision and coordination, neuropathology, statistical analysis, manuscript preparation.

\section{Data availability}

7 Data are available via ProteomeXchange with identifier PXD020020 (Project DOI: 10.6019/PXD020020). All files have been uploaded. These include all mass spectrometry raw files $(n=218)$ across four fractions and protein quantification results.

\section{Supporting information}

12 Additional supporting information can be found online in the Supporting Information section 13 at the end of the article

\section{Figure legends}

Figure 1: Schematic representation of the sequential pattern of neocortical proteome changes

21 in Alzheimer's disease pathogenesis. The first stage of this process was observed in p-preAD cases when $\mathrm{A} \beta$ plaques were found in the neocortex but no AD-related p-tau pathology. Here, distinct early-responding proteins showed changed levels in soluble, dispersible or SDS fractions of the homogenates from neocortex samples. Fraction shifts were not observed. Nonsignificant changes may be present in the gradually-changing proteins at this stage. Vesicle endocytosis and the secretory pathway-related processes were over-represented gene ontology terms already associated with p-preAD. The second stage of proteome pattern alterations was observed in symAD cases and associated with more proteins exhibiting increased or decreased levels in one or more fractions as well as showing fraction shifts. More biological functions, 
1 such as "caspase-mediated cleavage of cytoskeletal proteins" and "synaptic vesicle cycle", were

2 over-represented in this stage. This proteome pattern went along with the development of neocortical p-tau pathology and the clinical manifestation of the disease. To depict the possible functional impact of the proteome changes in p-preAD and $\mathrm{AD}$, we used the example of the synapse because the proteins with changes in p-preAD/symAD were mostly expressed in neurons or in the neuropil according to the human protein atlas [70] and the synaptic vesicle cycles was associated with AD in WGCNA analysis. Similar changes may also be seen in glial cells or other cells in neocortex during the pathogenesis of $\mathrm{AD}$. The fraction-shifting proteins are represented in blue, early-responding proteins in yellow, gradually-changing proteins in violet and late-responding proteins in red.

Figure 2: Differential levels of proteins identified throughout the progression of AD. a: Schematic representation of the experimental design. Immunohistochemistry for A $\beta$ and $p$-tau pathology in representative occipital neocortex sections from nonAD control (case No. Ctrl12), p-preAD (Case No. p-preAD9), and symAD cases (case No. symAD1). Black scale bars represent $500 \mu \mathrm{m}$, white scale bars $50 \mu \mathrm{m}$. Pieces of neocortex tissue from each case were homogenized and fractionated before being subjected to proteomic analysis. The soluble fraction contains soluble proteins, the dispersible fraction insoluble proteins, endo-, exo-, and synaptosomes in mixture with the intra- or extracellular fluid, the SDS fraction larger membrane particles, organelles and detergent soluble proteins, and the FA fraction amyloid-like and fibrillar protein aggregates that require FA for solubilizing. AD-related proteins including early- and late-responding, gradually-changing and fraction-shifting proteins were identified by level changes among nonAD, p-preAD, and symAD cases (Table S3, Figure S3, Suppl. Methods). b: Proteins that significantly changed between nonAD and p-preAD cases (earlyresponding proteins, in yellow), between p-preAD and symAD (late-responding proteins, in 
1 red), and between nonAD and symAD (gradually-changing proteins, in violet). Four proteins

2 fulfilling the criteria for gradually-changing proteins also met the criteria for early- or late-

3 responding proteins $(*)$ ). Details were presented in Figure S2-3 and Table S3; n: 18 non-AD,

418 p-preAD, 17 symAD. c. The levels of UCH-L1, secernin-1, plectin, hnRNP K, and phytanoyl-CoA hydroxylase-interacting protein-like (PHIPL_HUMAN) decreased in the soluble (red) and/or dispersible fraction (violet), and increased in the SDS fraction (blue), with the onset of AD symptoms (binary logistic regression controlled for age and sex, $\mathrm{p}<0.05$; Table S4a). Each protein was quantified based on the spectrum count and normalized to its mean quantity in cases with (=symAD) and without $\mathrm{AD}$ symptoms (=nonAD+p-preAD). Mean values (thick line) and \pm SEM (ribbon and thin line) of each protein from the respective fraction were plotted. For cases without AD symptoms (=nonAD+p-preAD), n=36; for symAD cases, n=17.

Figure 3: Protein-protein interaction networks analysis by STRING (confidence cutoff: 0.7).

a. Networks determined on the basis of functional/physical associations among AD-related gene products. The network analysis was performed with the Markov cluster algorithm using STRING Database (Suppl. Methods). The AD-related genes were obtained from [71] and [72] and represent the currently known GWAS-identified genetic risk factors and AD causative genes. b. Networks among the AD-related proteins as identified here. The network analysis was performed with the Markov cluster algorithm using STRING Database (Suppl. Methods). c. Network combining the AD-related genes studied in $\mathbf{a}$, and AD-related proteins analyzed in $\mathbf{b}$ in a genomic/proteomic hybrid network: $\mathbf{a}+\mathbf{b}=\mathbf{c}$. This analysis allows a view on the entire spectrum of AD-related proteins (based on this study) and AD-related genes (based on recent literature) and, thus, into the biological processes that are significantly affected in AD. Each circle represented one protein and/or gene depending on the label of the circle. Gene 
1 proteins including early- (yellow) and late-responding (red), gradually-changing (violet) and

2 fraction-shifting proteins (blue) determined in this study. Since some of the fraction-shifting

3 proteins also were late-responding or gradually-changing proteins, and one early-responding

4 protein was also a late-responding protein, their circles have two colors. The lines between

5 circles represented interactions/associations. Solid lines connected the circles of the same

6 cluster (intra-cluster associations/interactions), and dashed lines connected circles from

7 different ones (inter-cluster associations/interactions). The difference between the inter-cluster

8 (dashed lines) and the intra-cluster associations (solid lined) is the degree of similarity in

9 connectivity among functional and physical protein-protein interactions as determined by the

Markov cluster algorithm on the basis of the STRING Database (https://string-db.org). Non-

11 connected circles were not considered. Two connected circles without other connections to

12 neighboring circles were not taken into account in $\mathbf{c}$ but in $\mathbf{a}$ and $\mathbf{b}$. The colored dash frame

13 indicated three main clusters within the network, which grouped those proteins and genes that 14 are connected with at least one intra-cluster association. An exception from this rule was made 15 for the connections between APP/A $\beta$ and ADAM10 (the $\alpha$-secretase that catalyzes APP 16 cleavage in the center of the A $\beta$ region) and PSEN1 (the active component of the $\gamma$-secretase 17 that catalyzes the cleavage of the APP C-terminal fragment (APP-CTF) and releases A $\beta$ as a 18 result). The reason for considering these inter-cluster associations provided by the Markov 19 cluster algorithm as quasi intra-cluster associations is the respective biological function that 20 indicates a direct and causative relation of ADAM10 and PSEN1 to the cleavage of APP into $21 \mathrm{~A} \beta$ and/or other cleavage products.

23 Figure 4: Associations between early-, late-responding or gradually-changing proteins and AD 24 neuropathological parameters. a: Hierarchical clustering analysis of p-values from partial correlation analysis. In the heat-map, black is indicative of minimum p-value, red is indicative 
1 of $p=0.01$, yellow is indicative of $p=0.05$, and white is indicative of $p=1$. The protein names

2 of the early-responding proteins were written in yellow, those of the late-responding proteins

3 in red, and those of the gradually-changing proteins in violet. b: Hierarchical clustering analysis

4 of correlation coefficients from partial correlation analysis. In the heat-map, black is indicative of -1 , violet is indicative of -0.3 , orange is indicative of 0.3 , and red is indicative of $p=1$. The color code for proteins are the same with a. c: The box plots show the distribution of the following $\mathrm{AD}$-related neuropathological parameters among non $\mathrm{AD}$, p-pre $\mathrm{AD}$, and symAD cases: A $\beta$ phase, Braak NFT stage, CERAD scores, NIA-AA degree, stages and global severity of CAA, stages of GVD, occipital A $\beta$ load, occipital p-tau density score, occipital CAA severity, and the occipital presence of $\mathrm{A} \beta$ and p-tau pathology. The occipital p-tau density scores did not decide between AD-related and possibly chronic traumatic injury-like changes. This explains p-tau detection in the occipital lobe of few nonAD and p-preAD case. Linear regression analysis controlled for age and sex was performed. Between-group differences were determined using Kruskal-Wallis $\mathrm{H}$ test with multiple comparison of mean ranks, ${ }^{*} \mathrm{p}<0.05$, $* * \mathrm{p}<0.01, * * * \mathrm{p}<0.001$. Center line, median; box limits, upper and lower quartiles; whiskers, 1.5x interquartile range; circle, outliers. a, b and c: n: 18 nonAD, 18 p-preAD, 17 symAD.

\section{References}

[1] Alzheimer's Association. 2016 Alzheimer's disease facts and figures. Alzheimers Dement. 20 2016;12:459-509.

21 [2] Alzheimer A. Ueber eine eigenartige Erkrankung der Hirnrinde. Allg Zschr Psych. 1907;64:146-8.

[3] Grundke-Iqbal I, Iqbal K, Quinlan M, Tung YC, Zaidi MS, Wisniewski HM. Microtubule-associated protein tau. A component of Alzheimer paired helical filaments. J Biol Chem. 1986;261:6084-9.

[4] Masters CL, Simms G, Weinman NA, Multhaup G, McDonald BL, Beyreuther K. Amyloid plaque core protein in Alzheimer disease and Down syndrome. Proc Natl Acad Sci U S A. 1985;82:4245-9.

[5] Rijal Upadhaya A, Kosterin I, Kumar S, Von Arnim C, Yamaguchi H, Fändrich M, et al. Biochemical stages of amyloid $\beta$-peptide aggregation and accumulation in the human brain and their association with symptomatic and pathologically-preclinical Alzheimer's disease. Brain. 2014;137:887-903.

[6] Thal DR, Rüb U, Orantes M, Braak H. Phases of Abeta-deposition in the human brain and its relevance for the development of AD. Neurology. 2002;58:1791-800.

[7] Braak H, Braak E. Neuropathological stageing of Alzheimer-related changes. Acta Neuropathol. 1991;82:239-59. 
[8] Braak H, Thal DR, Ghebremedhin E, Del Tredici K. Stages of the pathological process in Alzheimer's disease: Age categories 1 year to 100 years. J Neuropathol Exp Neurol. 2011;70:960-9.

[9] Hyman BT, Phelps CH, Beach TG, Bigio EH, Cairns NJ, Carrillo MC, et al. National Institute on AgingAlzheimer's Association guidelines for the neuropathologic assessment of Alzheimer's disease. Alzheimers Dement. 2012;8:1-13.

[10] Crary JF, Trojanowski JQ, Schneider JA, Abisambra JF, Abner EL, Alafuzoff I, et al. Primary agerelated tauopathy (PART): a common pathology associated with human aging. Acta Neuropathol. 2014;128:755-66.

[11] Drummond E, Nayak S, Pires G, Ueberheide B, Wisniewski T. Isolation of Amyloid Plaques and Neurofibrillary Tangles from Archived Alzheimer's Disease Tissue Using Laser-Capture Microdissection for Downstream Proteomics. Methods Mol Biol. 2018;1723:319-34.

[12] Johnson ECB, Dammer EB, Duong DM, Ping L, Zhou M, Yin L, et al. Large-scale proteomic analysis of Alzheimer's disease brain and cerebrospinal fluid reveals early changes in energy metabolism associated with microglia and astrocyte activation. Nat Med. 2020.

[13] Donovan LE, Higginbotham L, Dammer EB, Gearing M, Rees HD, Xia Q, et al. Analysis of a membrane-enriched proteome from postmortem human brain tissue in Alzheimer's disease. Proteomics Clin Appl. 2012;6:201-11.

[14] Hales CM, Dammer EB, Deng Q, Duong DM, Gearing M, Troncoso JC, et al. Changes in the detergent-insoluble brain proteome linked to amyloid and tau in Alzheimer's Disease progression. Proteomics. 2016;16:3042-53.

[15] Seyfried NT, Dammer EB, Swarup V, Nandakumar D, Duong DM, Yin L, et al. A Multi-network Approach Identifies Protein-Specific Co-expression in Asymptomatic and Symptomatic Alzheimer's Disease. Cell Syst. 2017;4:60-72 e4.

[16] Hondius DC, van Nierop P, Li KW, Hoozemans JJ, van der Schors RC, van Haastert ES, et al. Profiling the human hippocampal proteome at all pathologic stages of Alzheimer's disease. Alzheimers Dement. 2016;12:654-68.

[17] Mendonca CF, Kuras M, Nogueira FCS, Pla I, Hortobagyi T, Csiba L, et al. Proteomic signatures of brain regions affected by tau pathology in early and late stages of Alzheimer's disease. Neurobiol Dis. 2019;130:104509.

[18] Harper JD, Wong SS, Lieber CM, Lansbury PT. Observation of metastable Abeta amyloid protofibrils by atomic force microscopy. Chem Biol. 1997;4:119-25.

[19] Walsh DM, Lomakin A, Benedek GB, Condron MM, Teplow DB. Amyloid beta-protein fibrillogenesis. Detection of a protofibrillar intermediate. J Biol Chem. 1997;272:22364-72.

[20] Kayed R, Head E, Thompson JL, McIntire TM, Milton SC, Cotman CW, et al. Common structure of soluble amyloid oligomers implies common mechanism of pathogenesis. Science. 2003;300:486-9.

[21] Lesne S, Koh MT, Kotilinek L, Kayed R, Glabe CG, Yang A, et al. A specific amyloid-beta protein assembly in the brain impairs memory. Nature. 2006;440:352-7.

[22] Habicht G, Haupt C, Friedrich RP, Hortschansky P, Sachse C, Meinhardt J, et al. Directed selection of a conformational antibody domain that prevents mature amyloid fibril formation by stabilizing Abeta protofibrils. Proc Natl Acad Sci U S A. 2007;104:19232-7.

[23] Shankar GM, Li S, Mehta TH, Garcia-Munoz A, Shepardson NE, Smith I, et al. Amyloid-beta protein dimers isolated directly from Alzheimer's brains impair synaptic plasticity and memory. Nat Med. 2008;14:837-42.

[24] Rijal Upadhaya A, Capetillo-Zarate E, Kosterin I, Abramowski D, Kumar S, Yamaguchi H, et al. Dispersible amyloid $\beta$-protein oligomers, protofibrils, and fibrils represent diffusible but not soluble aggregates: Their role in neurodegeneration in amyloid precursor protein (APP) transgenic mice. Neurobiol Aging. 2012;33:2641-60.

[25] Hung MC, Link W. Protein localization in disease and therapy. J Cell Sci. 2011;124:3381-92.

[26] Vendruscolo M, Knowles TP, Dobson CM. Protein solubility and protein homeostasis: a generic view of protein misfolding disorders. Cold Spring Harb Perspect Biol. 2011;3. 
[27] Pace MC, Xu G, Fromholt S, Howard J, Crosby K, Giasson BI, et al. Changes in proteome solubility indicate widespread proteostatic disruption in mouse models of neurodegenerative disease. Acta Neuropathol. 2018;136:919-38.

[28] Wesseling H, Mair W, Kumar M, Schlaffner CN, Tang S, Beerepoot P, et al. Tau PTM Profiles Identify Patient Heterogeneity and Stages of Alzheimer's Disease. Cell. 2020;183:1699-713 e13.

[29] Higginbotham L, Dammer EB, Duong DM, Modeste E, Montine TJ, Lah JJ, et al. Network Analysis of a Membrane-Enriched Brain Proteome across Stages of Alzheimer's Disease. Proteomes. 2019;7.

[30] McKetney J, Runde RM, Hebert AS, Salamat S, Roy S, Coon JJ. Proteomic Atlas of the Human Brain in Alzheimer's Disease. J Proteome Res. 2019;18:1380-91.

[31] Andreev VP, Petyuk VA, Brewer HM, Karpievitch YV, Xie F, Clarke J, et al. Label-free quantitative LC-MS proteomics of Alzheimer's disease and normally aged human brains. J Proteome Res. 2012;11:3053-67.

[32] Musunuri S, Wetterhall M, Ingelsson M, Lannfelt L, Artemenko K, Bergquist J, et al. Quantification of the brain proteome in Alzheimer's disease using multiplexed mass spectrometry. J Proteome Res. 2014;13:2056-68.

[33] Xu J, Patassini S, Rustogi N, Riba-Garcia I, Hale BD, Phillips AM, et al. Regional protein expression in human Alzheimer's brain correlates with disease severity. Commun Biol. 2019;2:43.

[34] Bai B, Wang X, Li Y, Chen PC, Yu K, Dey KK, et al. Deep Multilayer Brain Proteomics Identifies Molecular Networks in Alzheimer's Disease Progression. Neuron. 2020;106:700.

[35] Thal DR, Capetillo-Zarate E, Del Tredici K, Braak H. The development of amyloid beta protein deposits in the aged brain. Sci Aging Knowledge Environ. 2006;2006:re1.

[36] Hurtado DE, Molina-Porcel L, Iba M, Aboagye AK, Paul SM, Trojanowski JQ, et al. A\{beta\} Accelerates the Spatiotemporal Progression of Tau Pathology and Augments Tau Amyloidosis in an Alzheimer Mouse Model. Am J Pathol. 2010;177:1977-88.

[37] Hanseeuw BJ, Betensky RA, Jacobs HIL, Schultz AP, Sepulcre J, Becker JA, et al. Association of Amyloid and Tau With Cognition in Preclinical Alzheimer Disease: A Longitudinal Study. JAMA Neurol. 2019.

[38] Hanseeuw BJ, Betensky RA, Mormino EC, Schultz AP, Sepulcre J, Becker JA, et al. PET staging of amyloidosis using striatum. Alzheimers Dement. 2018;14:1281-92.

[39] Schwarz AJ, Yu P, Miller BB, Shcherbinin S, Dickson J, Navitsky M, et al. Regional profiles of the candidate tau PET ligand 18F-AV-1451 recapitulate key features of Braak histopathological stages. Brain. 2016;139:1539-50.

[40] Spires-Jones TL, Attems J, Thal DR. Interactions of pathological proteins in neurodegenerative diseases. Acta Neuropathol. 2017;134:187-205.

[41] Drummond E, Nayak S, Faustin A, Pires G, Hickman RA, Askenazi M, et al. Proteomic differences in amyloid plaques in rapidly progressive and sporadic Alzheimer's disease. Acta Neuropathol. 2017;133:933-54.

[42] Kamphuis W, Mamber C, Moeton M, Kooijman L, Sluijs JA, Jansen AH, et al. GFAP isoforms in adult mouse brain with a focus on neurogenic astrocytes and reactive astrogliosis in mouse models of Alzheimer disease. PLoS One. 2012;7:e42823.

[43] Challa AA, Stefanovic B. A novel role of vimentin filaments: binding and stabilization of collagen mRNAs. Mol Cell Biol. 2011;31:3773-89.

[44] Milton ID, Banner SJ, Ince PG, Piggott NH, Fray AE, Thatcher N, et al. Expression of the glial glutamate transporter EAAT2 in the human CNS: an immunohistochemical study. Brain Res Mol Brain Res. 1997;52:17-31.

[45] Woltjer RL, Duerson K, Fullmer JM, Mookherjee P, Ryan AM, Montine TJ, et al. Aberrant detergentinsoluble excitatory amino acid transporter 2 accumulates in Alzheimer disease. J Neuropathol Exp Neurol. 2010;69:667-76.

[46] Garcia-Esparcia P, Diaz-Lucena D, Ainciburu M, Torrejon-Escribano B, Carmona M, Llorens F, et al. Glutamate Transporter GLT1 Expression in Alzheimer Disease and Dementia With Lewy Bodies. Front Aging Neurosci. 2018;10:122. 
[47] Thal DR. Excitatory amino acid transporter EAAT-2 in tangle-bearing neurons in Alzheimer's disease. Brain Pathol. 2002;12:405-11.

[48] Kowal J, Tkach M. Dendritic cell extracellular vesicles. Int Rev Cell Mol Biol. 2019;349:213-49.

[49] McGeer PL, Itagaki S, Tago H, McGeer EG. Reactive microglia in patients with senile dementia of the Alzheimer type are positive for the histocompatibility glycoprotein HLA-DR. Neurosci Lett. 1987;79:195-200.

[50] Gomes LA, Lopez-Sanmartin D, Tomé SO, Tousseyn , Vandenberghe R, Vandenbulcke M, von Arnim CAF, Verstreken P, Thal DR. Maturation of neuronal AD-tau pathology involves site-specific phosphorylation of cytoplasmic and synaptic tau preceding conformational change and fibril formation. Acta Neuropathol 2021; 141:173-192.

[51] Pensalfini A, Kim S, Subbanna S, Bleiwas C, Goulbourne CN, Stavrides PH, et al. Endosomal Dysfunction Induced by Directly Overactivating Rab5 Recapitulates Prodromal and Neurodegenerative Features of Alzheimer's Disease. Cell Rep. 2020;33:108420.

[52] Braak H, Del Tredici K. The pathological process underlying Alzheimer's disease in individuals under thirty. Acta Neuropathol. 2011;121:171-81.

[53] Rub U, Del Tredici K, Schultz C, Thal DR, Braak E, Braak H. The evolution of Alzheimer's diseaserelated cytoskeletal pathology in the human raphe nuclei. Neuropathology and applied neurobiology. 2000;26:553-67.

[54] Sassin I, Schultz C, Thal DR, Rub U, Arai K, Braak E, et al. Evolution of Alzheimer's disease-related cytoskeletal changes in the basal nucleus of Meynert. Acta Neuropathol. 2000;100:259-69.

[55] Trinczek B, Ebneth A, Mandelkow EM, Mandelkow E. Tau regulates the attachment/detachment but not the speed of motors in microtubule-dependent transport of single vesicles and organelles. $J$ Cell Sci. 1999;112 ( Pt 14):2355-67.

[56] Ebneth A, Godemann R, Stamer K, Illenberger S, Trinczek B, Mandelkow E. Overexpression of tau protein inhibits kinesin-dependent trafficking of vesicles, mitochondria, and endoplasmic reticulum: implications for Alzheimer's disease. J Cell Biol. 1998;143:777-94.

[57] Alves RN, Iglesia RP, Prado MB, Melo Escobar MI, Boccacino JM, Fernandes CFL, et al. A New Take on Prion Protein Dynamics in Cellular Trafficking. Int J Mol Sci. 2020;21.

[58] Godsave SF, Peters PJ, Wille H. Subcellular distribution of the prion protein in sickness and in health. Virus Res. 2015;207:136-45.

[59] Campana V, Sarnataro D, Zurzolo C. The highways and byways of prion protein trafficking. Trends Cell Biol. 2005;15:102-11.

[60] Lauren J, Gimbel DA, Nygaard HB, Gilbert JW, Strittmatter SM. Cellular prion protein mediates impairment of synaptic plasticity by amyloid-beta oligomers. Nature. 2009;457:1128-32.

[61] Gomes LA, Hipp SA, Rijal Upadhaya A, Balakrishnan K, Ospitalieri S, Koper MJ, et al. Abeta-induced acceleration of Alzheimer-related tau-pathology spreading and its association with prion protein. Acta Neuropathol. 2019;138:913-41.

[62] Corbett GT, Wang Z, Hong W, Colom-Cadena M, Rose J, Liao M, et al. PrP is a central player in toxicity mediated by soluble aggregates of neurodegeneration-causing proteins. Acta Neuropathol. 2020;139:503-26.

[63] Velayos JL, Irujo A, Cuadrado-Tejedor M, Paternain B, Moleres FJ, Ferrer V. The cellular prion protein and its role in Alzheimer disease. Prion. 2009;3:110-7.

[64] Whitehouse IJ, Miners JS, Glennon EB, Kehoe PG, Love S, Kellett KA, et al. Prion protein is decreased in Alzheimer's brain and inversely correlates with BACE1 activity, amyloid-beta levels and Braak stage. PLoS One. 2013;8:e59554.

[65] Vonsattel JP, Myers RH, Hedley-Whyte ET, Ropper AH, Bird ED, Richardson EP, Jr. Cerebral amyloid angiopathy without and with cerebral hemorrhages: a comparative histological study. Ann Neurol. 1991;30:637-49.

[66] Thal DR, Ghebremedhin E, Orantes M, Wiestler OD. Vascular pathology in Alzheimer disease: correlation of cerebral amyloid angiopathy and arteriosclerosis/lipohyalinosis with cognitive decline. J Neuropathol Exp Neurol. 2003;62:1287-301. 
[67] Thal DR, Del Tredici K, Ludolph AC, Hoozemans JJ, Rozemuller AJ, Braak H, et al. Stages of granulovacuolar degeneration: their relation to Alzheimer's disease and chronic stress response. Acta Neuropathol. 2011;122:577-89.

[68] Mirra SS, Heyman A, McKeel D, Sumi SM, Crain BJ, Brownlee LM, et al. The Consortium to Establish a Registry for Alzheimer's Disease (CERAD). Part II. Standardization of the neuropathologic assessment of Alzheimer's disease. Neurology. 1991;41:479-86.

[69] Morris JC, Heyman A, Mohs RC, Hughes JP, van Belle G, Fillenbaum G, et al. The Consortium to Establish a Registry for Alzheimer's Disease (CERAD). Part I. Clinical and neuropsychological assessment of Alzheimer's disease. Neurology. 1989;39:1159-65.

[70] Uhlen M, Fagerberg L, Hallstrom BM, Lindskog C, Oksvold P, Mardinoglu A, et al. Proteomics. Tissue-based map of the human proteome. Science. 2015;347:1260419.

[71] Cuyvers E, Sleegers K. Genetic variations underlying Alzheimer's disease: evidence from genomewide association studies and beyond. Lancet Neurol. 2016;15:857-68.

[72] de Rojas I, Moreno-Grau S, Tesi N, Grenier-Boley B, Andrade V, Jansen I, et al. Common variants in Alzheimer's disease: Novel association of six genetic variants with $A D$ and risk stratification by polygenic risk scores. medRxiv. 2020:19012021.

[73] Fernandez-de Frutos M, Galan-Chilet I, Goedeke L, Kim B, Pardo-Marques V, Perez-Garcia A, et al. MicroRNA 7 Impairs Insulin Signaling and Regulates Abeta Levels through Posttranscriptional Regulation of the Insulin Receptor Substrate 2, Insulin Receptor, Insulin-Degrading Enzyme, and Liver X Receptor Pathway. Mol Cell Biol. 2019;39.

[74] Fukuda T, Naiki T, Saito M, Irie K. hnRNP K interacts with RNA binding motif protein 42 and functions in the maintenance of cellular ATP level during stress conditions. Genes Cells. 2009;14:11328.

[75] Pires G, McElligott S, Drusinsky S, Halliday G, Potier MC, Wisniewski T, et al. Secernin-1 is a novel phosphorylated tau binding protein that accumulates in Alzheimer's disease and not in other tauopathies. Acta Neuropathol Commun. 2019;7:195.

[76] Fu H, Ge B, Chen D, Wu Y, Luo Q, Li X, et al. Phytanoyl-CoA 2-Hydroxylase-Interacting Protein-Like Gene Is a Therapeutic Target Gene for Glioblastoma Multiforme. Med Sci Monit. 2019;25:2583-90.

[77] Rogaev El, Sherrington R, Rogaeva EA, Levesque G, Ikeda M, Liang Y, et al. Familial Alzheimer's disease in kindreds with missense mutations in a gene on chromosome 1 related to the Alzheimer's disease type 3 gene. Nature. 1995;376:775-8.

[78] Sherrington R, Rogaev El, Liang Y, Rogaeva EA, Levesque G, Ikeda M, et al. Cloning of a gene bearing missense mutations in early-onset familial Alzheimer's disease. Nature. 1995;375:754-60.

[79] Chartier-Harlin MC, Crawford F, Houlden H, Warren A, Hughes D, Fidani L, et al. Early-onset Alzheimer's disease caused by mutations at codon 717 of the beta-amyloid precursor protein gene. Nature. 1991;353:844-6.

[80] Goate A, Chartier-Harlin MC, Mullan M, Brown J, Crawford F, Fidani L, et al. Segregation of a missense mutation in the amyloid precursor protein gene with familial Alzheimer's disease. Nature. 1991;349:704-6.

[81] St George-Hyslop P, Haines J, Rogaev E, Mortilla M, Vaula G, Pericak-Vance M, et al. Genetic evidence for a novel familial Alzheimer's disease locus on chromosome 14. Nat Genet. 1992;2:330-4. [82] Szklarczyk D, Gable AL, Lyon D, Junge A, Wyder S, Huerta-Cepas J, et al. STRING v11: proteinprotein association networks with increased coverage, supporting functional discovery in genomewide experimental datasets. Nucleic Acids Res. 2019;47:D607-D13.

[83] Langfelder P, Horvath S. WGCNA: an R package for weighted correlation network analysis. BMC Bioinformatics. 2008;9:559. 


\section{Diagnosis}

nonAD (control)

$A \beta$ and $p$-tau pathology distribution in neocortex

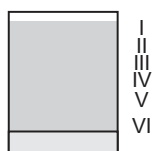

Stages of neocortical proteome changes

Soluble fraction

Dispersible fraction

SDS fraction

Formic acid fraction

Stage 0
p-preAD

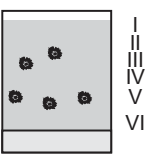

Stage 1
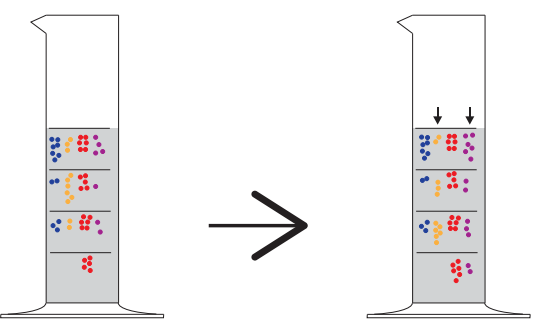

symAD

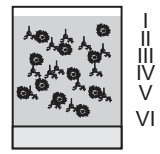

Stage 2
- A $\beta$ plaque

NFT-containing neuron

AD-related proteins

- Early-responding

- Gradually-changing

- Late-responding

- Fraction-shifting

Early endosome

- Vesicle

Synaptic vesicle presumbly with synaptotagmin-2

$\square \square$ Endocytosis and secretory pathway associated proteins (AP2 and clathrin)

- Endophilin-A1

- Ras-related protein Rab-3A 
A

Functional networks among AD-related genes

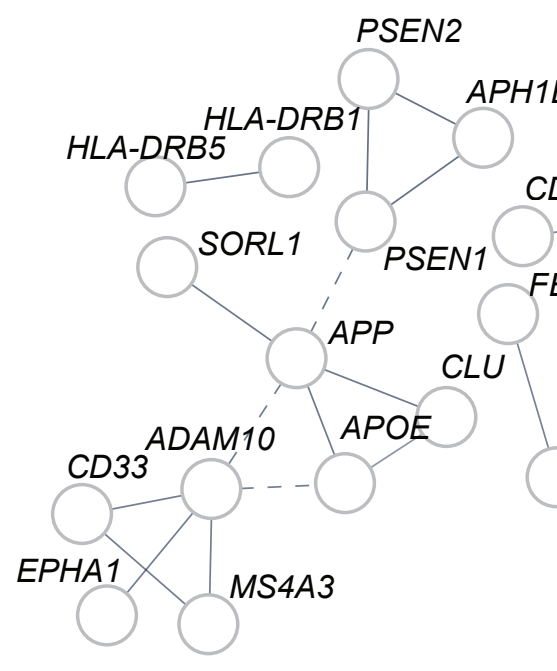

C

PICALM

BIN1
B

Functional network among AD-related proteins

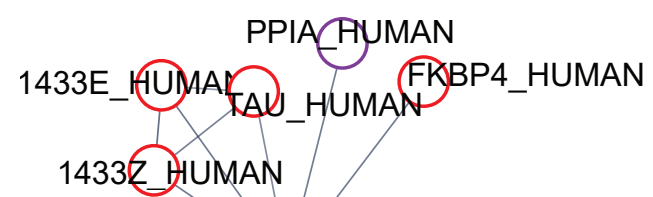

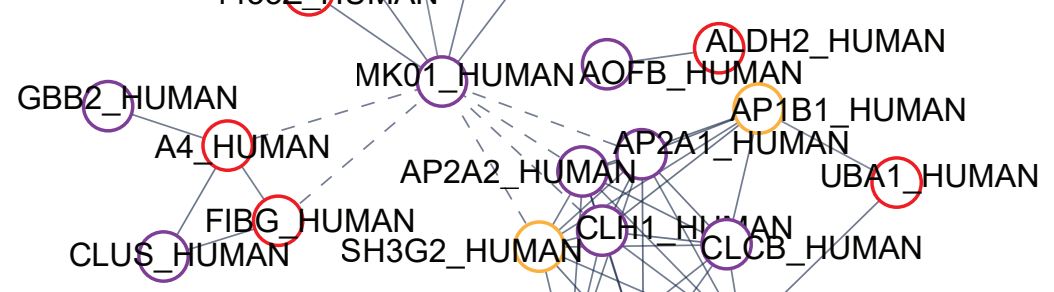

MS4A2
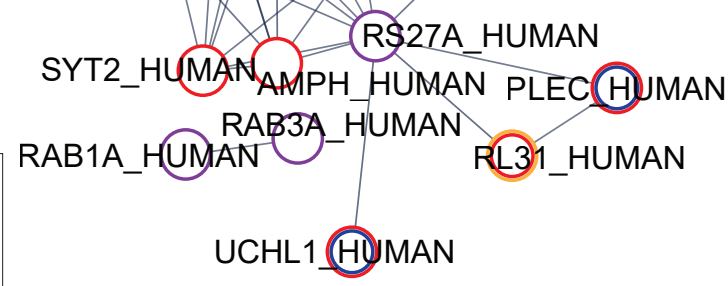

AD-related genes

- Late-responding proteins

- Gradually-changing proteins

O Fraction-shifting proteins

- Intra-cluster association

- - Inter-cluster association

Functional network associates AD-related genes with AD-related proteins

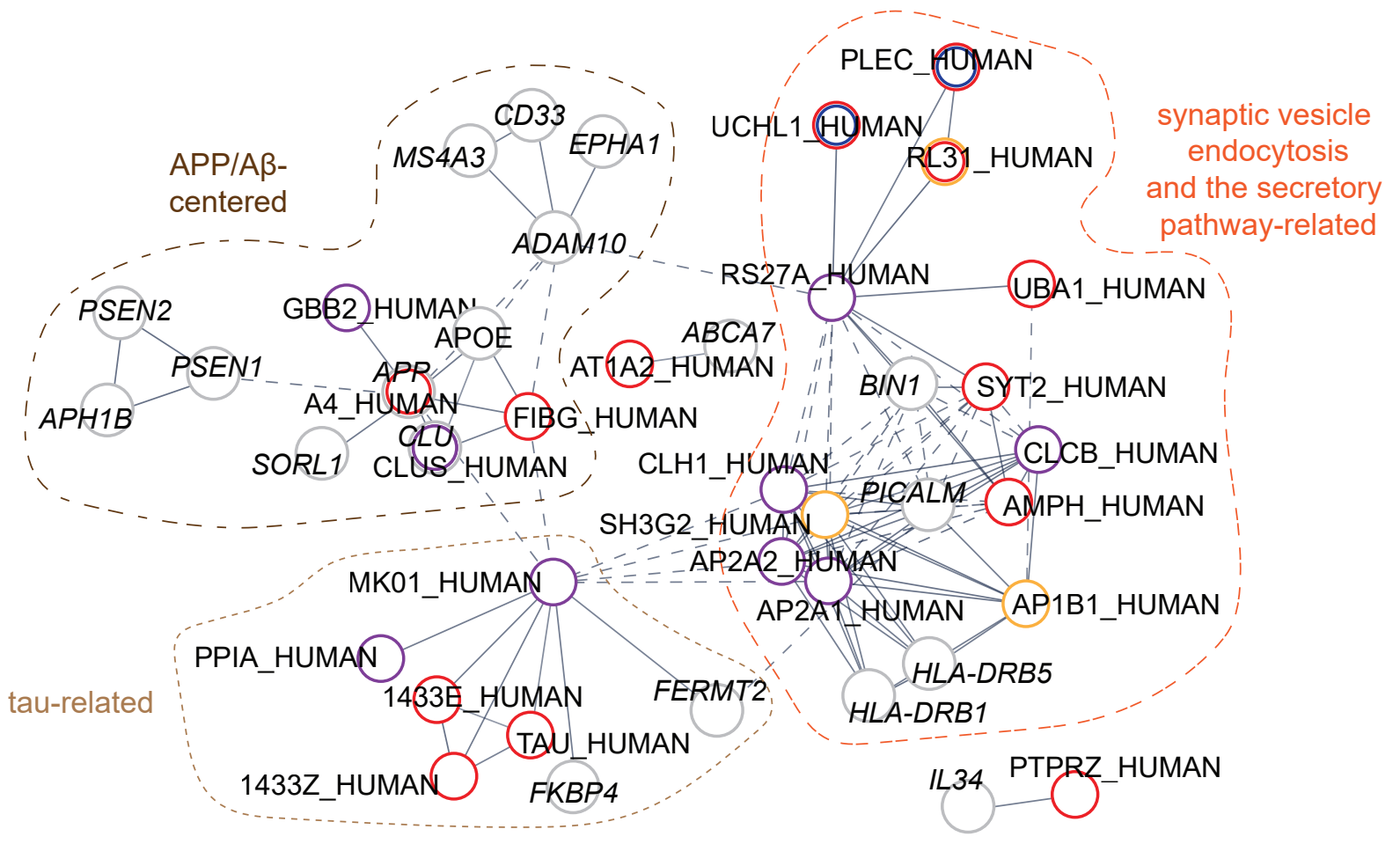


A

$10.01 \quad 005$ value

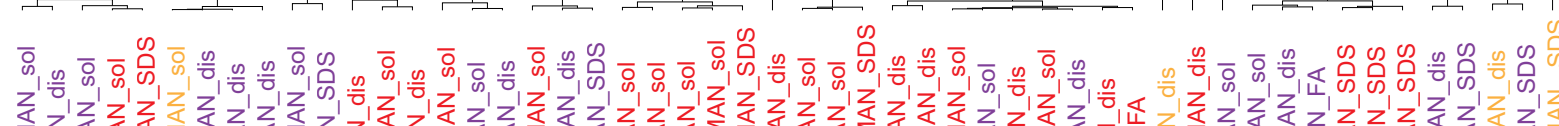

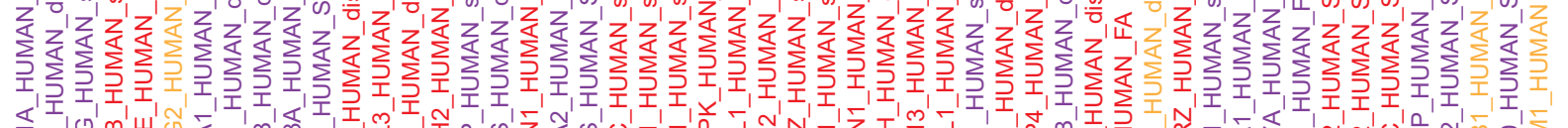

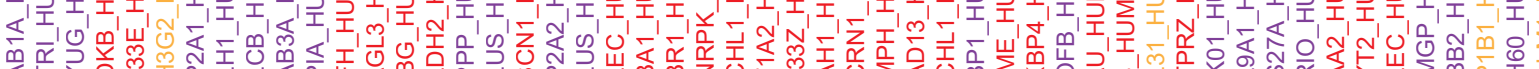

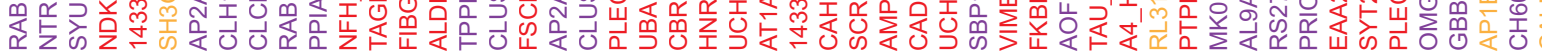

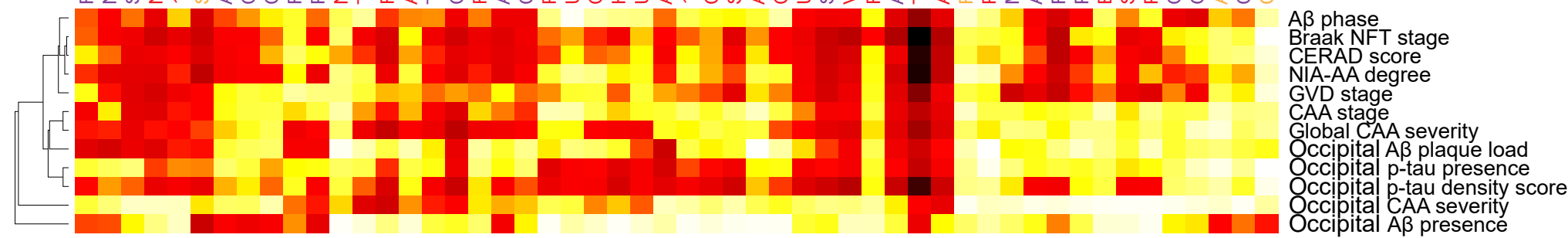

Late-responding Gradually-changing

$A \beta$ phase

Braak NFT stag NIA-AA degree GVD stage Global CAA severity Occipital A $\beta$ plaque load Occipity score Occipital CAA severity

B
$\begin{array}{lll}-1.00 & 0.00 \quad 1.00\end{array}$
correlation coefficient
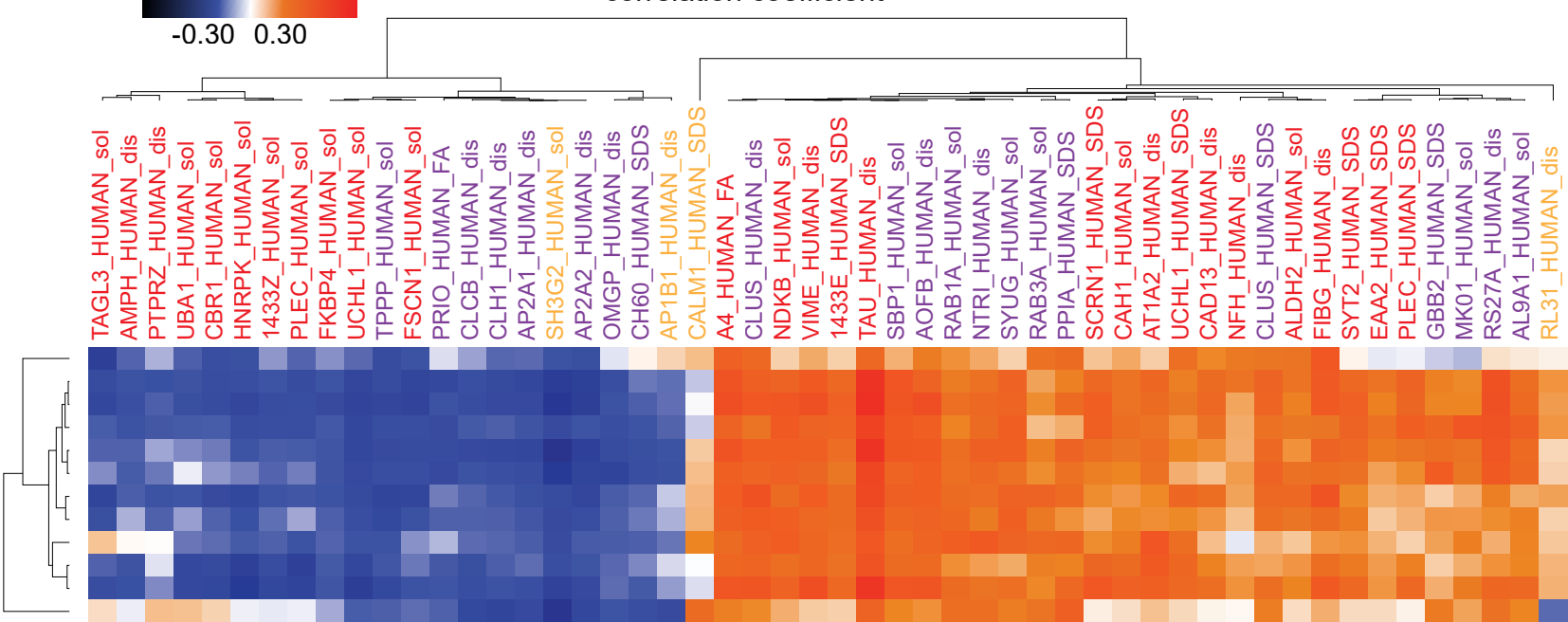

Occipital CAA severity CERAD score Braak NFT stage GVD stage NIA-AA degree $A \beta$ phase Global CAA severity CAA stage

Occipital $A \beta$ plaque load Occipital p-tau presence Occipital p-tau density score Occipital $A \beta$ presence

C

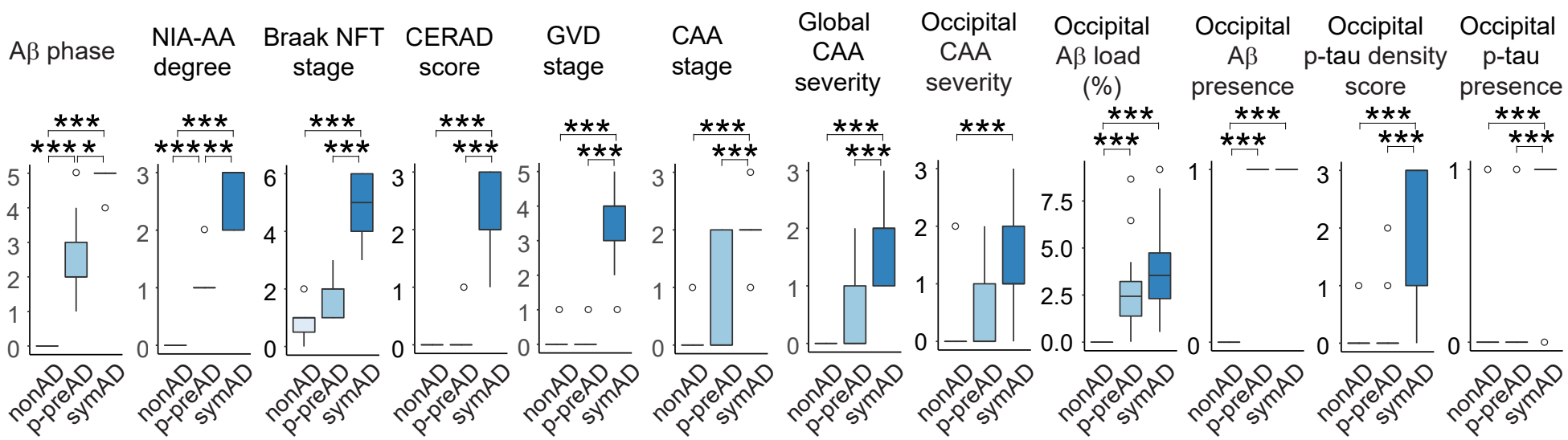




\section{Supporting information to:}

\section{Sequence of proteome profiles in preclinical and symptomatic Alzheimer's disease}

Xiaohang Li ${ }^{1,2}$ ORCID 0000-0002-7316-2196, Konstantinos C. Tsolis ${ }^{3}$, Marta J. Koper ${ }^{1,2,4,5}$, Alicja Ronisz $^{1,2} \underline{\text { ORCID 0000-0002-4310-0445 }}$, Simona Ospitalieri ${ }^{1,2}$, Christine A.F. von Arnim ${ }^{6,7} \underline{\text { ORCID 0000-0002- }}$ $\underline{8614-2223}$, Rik Vandenberghe ${ }^{8,9} \underline{\text { ORCID 0000-0001-6237-2502 }}$, Thomas Tousseyn ${ }^{10}$, Angelika Scheuerle ${ }^{11}$, Anastassios Economou ${ }^{3}$ ORCID 0000-0002-1770-507X, Sebastien Carpentier ${ }^{12}$ ORCID 0000-0002-7389-6405, Markus Otto ${ }^{6}$, Dietmar Rudolf Thal ${ }^{1,2,10}$ ORCID 0000-0002-1036-1075

\section{S1 Supplementary methods}

\section{S1.1 Human tissue and clinical characterization}

Human brains from 53 autopsy cases of both sexes (18 non-Alzheimer's disease (nonAD) controls (mean age $61 \pm 11.6$ years), 18 pathologically diagnosed preclinical AD (p-preAD) (mean age $70.3 \pm 8.2$ years) [1], and 17 symptomatic $\mathrm{AD}$ (symAD) cases (mean age $75.7 \pm 12.7$ years)) were investigated (Figure $2 \mathrm{a}$ and Table $\mathrm{S} 1$ ).

The brains were collected at university hospitals in Germany (Bonn and Ulm) and Belgium (Leuven). Autopsies were performed in accordance with German/Belgian law with informed consent of the next in kin and were used for this study after approval by the local ethical committees in Ulm/Germany (No. 86/13) and Leuven/Belgium (No. S-59295). Clinical dementia rating (CDR) scores were assessed retrospectively, as previously published [2]. In short, the non $\mathrm{AD}$ and p-preAD patients were examined at the time point of hospital admission (approximately 1 to 4 weeks prior to death) by clinicians with different specialties according to standardized protocols. The symAD patients were diagnosed by a neurologist (RV, CAFvA, MO) and followed up until death. The protocols included the assessment of cognitive function (orientation to place, time and person; specific cognitive or neuropsychiatric tests were not 
performed) and recorded the patients' ability to take care of themselves and to get dressed, eating habits, bladder and bowel continence, speech patterns, writing and reading ability, shortterm and long-term memory, and orientation within the hospital setting. These data were used to retrospectively assess the CDR scores for each patient [3] without knowledge of the pathological diagnosis. For this purpose, the information from the clinical files was used to provide a CDR score according to the standard CDR protocol [3].

To classify the cases as nonAD control, p-preAD and symAD we applied the following criteria: symAD was diagnosed when the clinical reports indicated cognitive deficits (clinical dementia rating (CDR)-score 1-3) and an intermediate or high degree of AD neuropathology according to the current recommendations for the neuropathological assessment of Alzheimer's disease pathology by the National Institute of Aging and the Alzheimer Association (NIA-AA) [4] (Table S1). Non-demented cases and cases with negligible cognitive deficits, i.e. CDR-score 0.5 or 0 , fulfilling the NIA-AA criteria for low-high degrees of AD pathology were classified as p-preAD cases as previously described [1] by considering the pathological detection of amyloid plaques and neurofibrillary tangles (NFTs) as AD biomarker [5]. This definition is in compliance with the biological definition of the Alzheimer continuum [6]. Non-demented control cases had a CDR-score of 0 and no AD pathology according to the NIA-AA recommendations. Primary age-related tauopathy (PART) cases were included in the control group. They were not separated from non-PART cases because occipital and frontal cortex (used for proteomic analysis) are not involved in PART [7].

Exclusion criteria for the cohorts in this study were neuropathological signs of inflammation in the frontal, parietal and occipital cortex, morphological evidence for general hypoxemia during brain autopsy, and hepatitis B or C infection, HIV infection, or a spongiform encephalopathy. Infarcts or bleedings outside the occipital/frontal cortex were not considered as exclusion criterion. 


\section{S1.2 Neuropathology}

The right brain hemispheres were cut without fixation. After dissection of the brainstem and cerebellum from the forebrain, the forebrain was cut into $1 \mathrm{~cm}$ frontal slabs. Brain stem and cerebellum were cut perpendicular to the Meynert brain stem axis in $0.5 \mathrm{~cm}$ slabs. These slabs were kept frozen at $-80^{\circ} \mathrm{C}$. The left brain hemispheres were fixed in a $4 \%$ aqueous or phosphatebuffered solution of formaldehyde for approx. 2-4 weeks. For histological assessments, tissue blocks from frontal (Brodmann area 6), parietal, and occipital lobe (Brodmann area 17-19), cingulate gyrus, hippocampus with temporal cortex, entorhinal cortex, hypothalamus, basal ganglia, amygdala, basal nucleus of Meynert, thalamus, midbrain, pons, medulla oblongata and cerebellum were dissected, embedded in paraffin and microtomed at 5-12 $\mu \mathrm{m}$. For neuropathological diagnosis, paraffin sections were stained with hematoxylin-eosin, anti-p-tau (pS202/pT205; clone AT8, MN1020, heat pretreatment at pH 6.0, dilution 1:1000, Thermo Fisher Scientific), anti-amyloid $\beta$-protein (A $\beta$ ) (anti-A $\beta_{17-24}$; clone 4G8, SIG-39220, pH 6.0 heat and formic acid pretreatment, dilution 1:1000, BioLegend), and anti-phosphorylated transactive response DNA binding protein $43 \mathrm{kDa}$ (pTDP-43 ${ }^{\mathrm{pS} 409 / \mathrm{pS} 410}$; polyclonal rabbit, heat pretreatment at $\mathrm{pH}$ 6.0, dilution 1:1000, Cosmo Bio) antibodies. None of the cases included in this study showed signs of hypoxemia-related neuronal damage.

The phase of $A \beta$ plaque pathology (A $\beta$ phase) was assessed after screening the $A \beta$-stained sections for plaque distribution according to previously published protocols [2]. One single amyloid plaque indicated that a given anatomical brain region was amyloid positive. Braakstages for NFT-expansion throughout the brain were determined as previously described based on anti-p-tau stained sections [8,9]. The frequency of p-tau-positive neuritic plaques was assessed according to the recommendations of the consortium to establish a registry for AD 
(CERAD) [10]. The National Institute of Aging-Alzheimer Association (NIA-AA) degree of AD pathology was determined according to Hyman et al [4].

The stage of cerebral amyloid angiopathy (CAA) pathology was determined based upon a previously published protocol [11]. In short, CAA was diagnosed when A $\beta$-deposits were found in the wall of cerebral and/or leptomeningeal blood vessels. CAA stage 1 describes CAA restricted to leptomeningeal and cortical vessels of neocortical brain regions. In CAA stage 2, allocortical and cerebellar blood vessels are additionally affected. An expansion of vascular A $\beta$ deposition into blood vessels of the white matter, basal ganglia, diencephalon, and/or the brain stem indicates CAA stage 3 .

The overall degree of CAA severity in the entire brain was determined according to Vonsattel et al. [12]: grade 1 was considered when blood vessels showed focal A $\beta$ deposits in the vessel wall; grade 2 was diagnosed in the event that vessels exhibited $\mathrm{A} \beta$ deposits in the entire vessel wall with smooth muscle cell damage; grade 3 was reserved to those cases that had signs of CAA-related hemorrhages.

The local, occipital CAA severity score was determined as follows: presence of meningeal CAA $=$ severity score 1 , cortical CAA = severity score 2 , and capillary CAA = severity score 3 . The reason for using this latter occipital CAA severity score to assess CAA in the occipital cortex was the assumption that we expected less impact on cortical protein expression in cases with only leptomeningeal CAA compared to cases with cortical CAA. Since capillary involvement may also go along with blood flow alterations we considered its presence as potentially more prone to induce protein level changes than that of CAA in only larger vessels.

Stages of granulovacuolar degeneration (GVD) [13] were determined based on the detection of pTDP-43-positive cytoplasmic vacuoles with granules [14] as follows: GVD stage $1=$ GVD in the CA1/subiculum region of the hippocampal formation; GVD stage $2=$ additional GVD lesions in CA4 and the entorhinal cortex; GVD stage $3=$ additional GVD lesions in the temporal 
neocortex (areas 35/36); GVD stage $4=$ additional GVD lesions in the amygdala and/or hypothalamus; and GVD stage 5 = additional GVD lesions in the temporal, parietal, or occipital neocortex.

The plaque load for $\mathrm{A} \beta$ (4G8)-positive plaques and p-tau-density scores were assessed as previously described $[15,16]$. In short, the $A \beta$ plaque load was determined as the percentage of the area covered by $\mathrm{A} \beta$-positive plaques in a reference area of the occipital neocortex (Brodmann area 17) (size of reference area: $\sim 1 \mathrm{~mm}^{2}$ ) covered by the respective plaques. The reference area covered all cortical layers. Morphometry was performed using ImageJ image processing and analysis software (National Institutes of Health, Bethesda, MD, USA).

The p-tau-density score was determined in the occipital cortex (Brodmann area 17) by the density of p-tau (AT8)-positive neuropil threads at magnifications $\times 100$ and $\times 200$ according to Alafuzoff et al. [16]. Low (+) was assigned if (AT8)-positive structures were barely noted at low magnification, moderate (++) was assigned if (AT8)-positive structures were easily seen at both magnifications, and high (+++) was assigned if (AT8)-positive structures were seen even without the microscope.

\section{S1.3 Preparation of human brain fractions for mass spectrometry analysis}

Fresh-frozen samples of the cortical ribbon $(\sim 100 \mathrm{mg})$ without adjacent white matter or leptomeninges were taken with a $3 \mathrm{~mm}$ diameter punching tool from occipital (Brodmann areas 17-19) ( $\mathrm{n}=51$ cases) or frontal (Brodmann area 6) ( $\mathrm{n}=2$ cases) neocortex and homogenized at $10 \%$ (weight/volume) in cold Tris-buffered saline (TBS) with a protease/phosphatase inhibitor cocktail. Frontal neocortex was only taken when occipital cortex samples were not available (n $=2$, control cases). Samples from occipital and frontal neocortex were taken for this study because here $A \beta$ pathology precedes the development of tau pathology [2, 9]. Accordingly, we can distinguish $A \beta$-related alterations from those seen in the presence of both, $A \beta$ and tau. We 
performed an unweighted sample clustering by using the R package for weighted correlation network analysis "WGCNA" [17] version 1.69 to detect outliers among controls. The two frontal samples are clustered together with the occipital samples (Figure S1). Thus, the proteome expression pattern can be considered as comparable among these two neocortex regions allowing the inclusion of both frontal and occipital cortex samples for controls.

Following homogenization with micro-pestle, samples were sonicated 6 times for $20 \mathrm{~s}$ with 10 s intervals of rest at $30 \%$ amplitude. Fractionation of the proteins was carried out as previously described [1]. In detail, the homogenates were centrifuged at $14000 \mathrm{x} \mathrm{g}$ for $30 \mathrm{~min}$ at $4{ }^{\circ} \mathrm{C}$, before we subjected the resulting supernatant (S1) with soluble, dispersible proteins (i.e., insoluble proteins in mixture with the extra- or intracellular fluid), endosomes, exosomes, and synaptosomes to ultracentrifugation at $121656 \mathrm{x} \mathrm{g}$ and $4{ }^{\circ} \mathrm{C}$ for $30 \mathrm{~min}$. We referred to the resulting supernatant after ultracentrifugation (S2) as "soluble fraction", and we resuspended the pellet after ultracentrifugation (P2) with TBS and we named it "dispersible fraction". Accordingly, the soluble fraction contained only soluble proteins whereas the dispersible fraction was considered to contain insoluble proteins (e.g. A $\beta$ oligomers and protofibrils [15]), endo-, exo- and synaptosomes that are in mixture with the extra- or intracellular fluid. The pellet received from the first $14000 \mathrm{x}$ g centrifugation step (P1) was resuspended in 2\% SDS, and sonicated 6 times for $20 \mathrm{~s}$ with $10 \mathrm{~s}$ intervals of rest at $30 \%$ amplitude, before we subjected it to a second $14000 \mathrm{x}$ g centrifugation step. The resulting supernatant (S3) was called "SDS fraction" and contains mainly membrane-associated proteins from larger organelles excluding endo-, exo-, and synaptosomes that are contained in the dispersible fraction. The respective pellet (P3) was resuspended in 70\% formic acid (FA) overnight at room temperature. Following another centrifugation step at $14000 \mathrm{x}$ g, the supernatant was collected and dried under vacuum. This fraction was referred to as "FA fraction" and contains highly aggregated proteins, including amyloid plaques from $\mathrm{AD}$ cases $[1,18]$. 
Chloroform/methanol precipitation was performed for SDS and FA fractions, and 2\% Rapigest (Waters) was used to dissolve the precipitated proteins. Protein concentration was determined by the bicinchoninic acid (BCA) assay (ThermoFisher).

For trypsin digestion, $2 \mu \mathrm{g}$ of total protein per fraction from each case was used. Proteins were treated with $1 \mathrm{mM}$ dithiothreitol and $10 \mathrm{mM}$ iodoacetamide in succession before trypsin (Pierce MS grade, Thermo Scientific) was added at a ratio of 1:100 to each sample. After an overnight incubation at $37^{\circ} \mathrm{C}$ in $50 \mathrm{mM}$ ammonium bicarbonate (Sigma), the reaction was stopped by 2 $\mu l$ trifluoroacetic acid (Sigma). Resulting peptides were desalted with C18 tips (3M Empore ${ }^{\mathrm{TM}}$ C18 disks; Sigma-Aldrich) and dried under vacuum.

\section{S1.4 Liquid Chromatography Coupled to Tandem Mass Spectrometry (LC-MS/MS)}

The desalted peptides (in $20 \mu \mathrm{L} 0.1 \%$ FA, $5 \%$ acetonitrile) were injected ( $5 \mu \mathrm{L}$ ) and separated on an Ultimate 3000 UPLC system (Dionex, Thermo Scientific) equipped with an Acclaim PepMap100 pre-column (C18 $3 \mu \mathrm{m}-100 \AA$, Thermo Scientific) and a C18 PepMap RSLC (2 $\mu \mathrm{m}, 50 \mu \mathrm{m}-15 \mathrm{~cm}$, Thermo Scientific) using a linear gradient ( $300 \mu \mathrm{L} / \mathrm{min})$ of $0-4 \%$ buffer B (80\% ACN, $0.08 \% \mathrm{FA}$ ) for $3 \mathrm{~min}, 4-10 \%$ B for $12 \mathrm{~min}, 10-35 \%$ B for $20 \mathrm{~min}, 35-65 \%$ B for $5 \mathrm{~min}, 65-95 \%$ B for $1 \mathrm{~min}, 95 \%$ B for $10 \mathrm{~min}, 95-5 \%$ B for $1 \mathrm{~min}$, and 5\% B for $10 \mathrm{~min}$. The Q Exactive Orbitrap mass spectrometer (Thermo Scientific) was operated in positive ion mode with a nanospray voltage of $1.5 \mathrm{kV}$ and a source temperature of $250^{\circ} \mathrm{C}$. Proteo Mass LTQ/FTHybrid ESI Pos Mode Cal Mix (MS CAL5-1EASUPELCO, Sigma-Aldrich) was used as an external calibrant and the lock mass 445.12003 as an internal calibrant. The instrument was operated in data-dependent acquisition (DDA) mode with a survey MS scan at a resolution of 70000 (FWHM at m/z 200) for the mass range of m/z 400-1600 for precursor ions, followed by MS/MS scans of the top ten most intense peaks with $+2,+3,+4$, and +5 charged ions above a threshold ion count of 16000 at 17500 resolution using normalized collision energy (NCE) of 
$25 \mathrm{eV}$ with an isolation window of $3.0 \mathrm{~m} / \mathrm{z}$ and dynamic exclusion of $10 \mathrm{~s}$. All data were acquired with Xcalibur 3.0.63 software (Thermo Scientific). Unless the intensity of the signal from the MS was too low, we ran each LC-MS/MS sample once.

\section{S1.5 Bioinformatics}

For protein identification, all data files were converted into .mgf format and processed using Mascot version 2.2.06 (Matrix Science) against a Uniprot homo sapiens database (Swiss-Prot, Homo sapiens, 20231 entries). The parameters used to search at Mascot were: parent tolerance of $10 \mathrm{PPM}$, fragment tolerance of $20 \mathrm{mmu}$, variable modification oxidation of $\mathrm{M}$ and deamidation of NQ, fixed modification with carbamidomethyl C, and up to two missed cleavage for trypsin. To calculate the false discovery rate (FDR) [19] and to perform the spectral counting, the sample-specific .dat files were loaded into Scaffold 4 (Proteome Software). The Scaffold4 setting was: X! Tandem Alanine (2017.2.1.4) as search engine; minimum one peptide with $95 \%$ confidence and allows only to report the set of proteins that leads to an FDR for proteins of $1.0 \%$. Proteins with $100 \%$ protein identification probability (Table S2) from at least one LC-MS/MS sample in a given fraction were subjected to further analysis. The quantitative value (normalized total spectra) was used for analyzing. It is important to note that our Mascot settings did not allow detection of p-tau. Only the physiological form of the tau protein was analyzed in this study by our proteomics approach.

Early-responding, late-responding, gradually-changing and fraction-shifting proteins together were referred to as "AD-related proteins" in this study. Protein modules showing a correlation with distinct AD pathology parameters in WGCNA were referred to as "AD-related modules". The over-representation of gene ontology (GO) terms of AD-related proteins or modules were analyzed by using the Database for Annotation, Visualization and Integrated Discovery (DAVID) [20, 21] (https://david.ncifcrf.gov/). GO term data were retrieved from curated 
databases that cover functional categories including UniProtKB keywords (UP_KEYWORDS), UniProtKB sequence feature (UP_SEQ_FEATURE), Cellular Component (GOTERM_CC_DIRECT), Molecular Function (GOTERM_MF_DIRECT), Biological Process (GOTERM_BP_DIRECT), REACTOME (REACTOME_PATHWAY) and KEGG (KEGG_PATHWAY). We did not include BioCARTA, because its coverage is lower than 50\% for our input list. The threshold defining an over-represented functional annotation was a minimum of two proteins being involved and EASE $<0.05(=p$-value based on Fisher's exact test describing the significance of the GO-term enrichment). The whole list of proteins detected in all samples was used as reference list (background). The fold of enrichment and Benjamini multiple testing correction were also calculated by DAVID.

The term "AD-related genes" was used to summarize all known AD-causative genes (APP, PSEN1 and PSEN2) [22-26] and all genes that exhibited AD-associated risk alleles in genome wide association studies (GWAS), such as the apolipoprotein E gene (APOE) [27-29]. The association of AD-related proteins and genes was analyzed under the framework of the search tool for the retrieval of interacting genes/proteins (STRING) [30] (https://string-db.org/) 1) separately for the AD-related genes and proteins and 2) in a common network including ADrelated genes and proteins. Information that indicated active interactions included experimental data, associations in curated databases, co-expression, neighborhood in genome, gene fusion and co-occurrence across genome. The cut-off for minimal required interaction score was 0.7 (high confidence). The network clustering used Markov Cluster (MCL) Algorithm with three inflations.

The human protein atlas [31] (https://www.proteinatlas.org/) was used to retrieve information about the distribution of all significantly changed proteins. Tissue protein expression pattern in normal cerebral cortex and cellular protein expression pattern according to the human protein atlas [31] are provided in Table S3. 


\section{S1.6 Statistical analysis}

Statistical analysis was carried out using Statistica 13 (TIBCO), R-project R4.03 (https://www.r-project.org/), IBM SPSS 26 (IBM) and G-Power (Universität Düsseldorf, Germany) software. The $\mathrm{N}$ throughout this study was nonAD (18 cases), p-preAD (18 cases), symAD (17 cases), unless stated otherwise. No imputation of missing values was performed in our cohort.

To analyze the obtained data we used both a supervised and an unsupervised approach independent from one another.

Supervised approach: To identify the significant difference in the levels of proteins among nonAD, p-preAD and symAD groups, Statistica 13 (TIBCO) was used and Kruskal-Wallis H test with multiple comparisons of mean ranks as post-hoc test was applied as the first step, and only proteins with $\mathrm{p}$ values less than 0.05 were considered significantly changed among groups. The same test was applied to all the neuropathological parameters.

Multinomial logistic regression controlled for age and sex or post-mortem interval (PMI), was carried out using p-preAD group as the reference category in a second analysis. Only those proteins that were identified in the first step as p-preAD changed proteins or that showed significant changes between p-preAD and symAD were included in this analysis. Furthermore, linear regression was performed by using the diagnosis score indicating the development of AD from non-affected nonAD brain to symAD brain $($ non $A D=0, p-p r e A D=1$, and $\operatorname{sym} A D=2)$ as dependent variable and the protein quantification of symAD changed proteins as independent variable, with age and sex, or PMI as covariates. Only when the p value of a specific protein was less than 0.05 , this protein was considered to be associated with the progression of $\mathrm{AD}$ from nonAD to p-preAD and to symAD.

Post-hoc power analysis was calculated based on mean values and carried out with G-power 3.1 (University of Düsseldorf). 
For partial correlation analysis, occipital $\mathrm{AD}$ lesion measurements, including occipital $\mathrm{A} \beta$ plaque load, occipital p-tau density score and occipital CAA severity score, and other AD neuropathology parameters, including A $\beta$ phase, Braak NFT, CERAD, GVD and CAA staging, overall CAA severity, as well as protein abundance were included, together with the control variables, such as age and sex or PMI. Only when the p value of a specific protein was less than 0.05 , this protein was considered to fit in our model. Transformed p values $(=\log (1 / \mathrm{p}))$ and the absolute values of correlation coefficients were used to plot the heat maps, and hierarchical clustering analysis was performed using Morpheus (https://software.broadinstitute.org/morpheus/). The setting was: linkage rule: complete linkage; distance measure: one minus cosine similarity.

To identify the significant difference in protein level between cohort without AD symptoms (nonAD + p-preAD) and AD symptomatic cohort, Statistica 13 was used and Mann-Whitney $\mathrm{U}$ Test with continuity correction was performed, and only proteins with p values less than 0.05 were considered to indicated significant changes between the groups.

For binary logistic regression analysis comparing cases without AD symptoms with symAD cases, nonAD and p-preAD cases were set as 0 , and symAD cases as 1 . Protein abundance, age and sex were used as covariates. The relationship between the protein abundance and the presence or absence of symAD was thereby analyzed.

Unsupervised approach: Analysis using the WGCNA algorism [17] was performed using the R package "WGCNA" (version 1.69). The WGCNA "blockwiseModules()" function was used with the following settings: soft threshold power $\beta=6$, "deepSplit" =2, "TOMType" = "unsigned", minimum module size of 30, "reassignThreshold" = 0 , merge cut height of 0.25 . In WGCNA (Figure S4), all proteins that were detected in this study were subjected to the analysis. To assess those proteins that do not show collinearity with age and/or sex for their contribution to $\mathrm{AD}$ pathogenesis, we pre-filtered the protein data set (Figure S5). To do so, we performed 
linear regression analysis for all proteins in this study and determined the association between their levels and age and sex. Proteins of which the abundances were associated with age and/or sex were excluded from the second WGCNA analysis of this pre-filtered dataset.

\section{S2 Additional detailed discussion}

S2.1 Early involvement of vesicle endocytosis and the secretory pathway-related processes in the pathogenesis of $A D$

GO over-representation analysis showed an enrichment of vesicle endocytosis and the secretory pathway-related processes in the proteome of $\mathrm{p}$-preAD and symAD. The number of overrepresented GO terms increased when late-responding, gradually-changing and fractionshifting proteins became significantly involved in symAD. This argues in favor of the concept that cases classified as p-preAD indeed show an earlier stage of the changes observed in symAD. Moreover, vesicle endocytosis and the secretory pathway-related processes appear to represent a third, early involved, pathogenetically relevant component in $\mathrm{AD}$, in addition to A $\beta / A P P$ and tau-related disease component. This hypothesis is supported by the results of the protein-protein interaction network analysis including the AD-related proteins identified in this study and the known AD-related genes. It indicates a cluster of proteins/genes related to vesicle endocytosis and the secretory pathway-related processes. A second argument supporting this hypothesis is the finding that especially early-responding proteins were frequently associated with the respective GO terms. Remarkably, this finding may be related to our protein extraction protocol. Fractionation of the brain homogenates with separation of endo-, exo-, and synaptosomes may have increased the likelihood to detect changes in endocytosis and the secretory pathway by enriching the respective proteins in the dispersible fraction. Possible sources of bias in the GO or network analysis are the selection of literature that were taken to 
find the AD-related genes, their use as a predefined input, and the databases used that cover a given spectrum of information. Nevertheless, the large number of proteins and genes representing the newly identified $\mathrm{AD}$ component centered around vesicle endocytosis and the secretory pathway supports our interpretation. In addition, many of the proteins exhibiting changes in p-preAD and symAD in our analysis were also observed earlier as being related to AD [32-42]. Some of these protein, such as endophilin A (SH3G2_HUMAN) and calmodulin 1 are associated with synaptic vesicle endocytosis $[43,44]$. The synaptic vesicle cycle, vesicle endocytosis and the secretory pathway-related processes were over-represented as indicated by proteins in AD-associated modules derived by WGCNA (Figure S5, Table S5). This supports our hypothesis that these processes are critically involved in the pathogenesis of $\mathrm{AD}$ and represent a possible novel target for therapeutic approaches. Given the links between these processes, the involvement of secretory and endocytic systems in APP cleavage and A $\beta$ formation [45-53], tau as a regulator of axonal vesicle transport [54], and both $A \beta$ and tau as a potential exosome content $[51,55,56]$, our findings may help to clarify the mechanisms of $A \beta$ and p-tau-related cell damage.

The bulk increase of tau was observed in the dispersible fraction pointing to dispersible tauoligomers and protofibrils in mixture with the intra- or extracellular fluid of the brain as the major tau-containing fraction in the brain, which is similar to dispersible $A \beta$ representing $A \beta$ oligomers and protofibrils $[1,15]$. This is in line with the observation of tau-oligomers in the brain [57]. Moreover, fibrillar tau that is detected by specific silver staining techniques represents only a small part of the tau-pathology that can be observed with immunostainings using antibodies against $\mathrm{p}$-tau $[8,58,59]$. Since the settings for the peptide/protein identification precluded the detection of p-tau, it can actually expected that an increase of p-tau pathology cannot be observed. Soluble/dispersible or endosomal forms of tau aggregates may be discussed as relevant for the propagation of tau pathology as shown in cell culture experiments $[60,61]$ 
and animal experiments [62]. The contribution of non-phosphorylated tau in such aggregates may be documented by the increase of tau in the dispersible fraction in this study while p-tau accumulated in NFTs and neuropil threads as shown immunohistochemically.

Soluble/dispersible forms of A $\beta$ may also interact with these processes because intracellular forms of $A \beta$ are mainly located in the lysosomal/endosomal compartment [53,63]. Therefore, an impairment of lysosomal/endosomal function in vesicle endocytosis and the secretory pathway by intracellular $A \beta$ as shown in cell culture [64] appears to be possible. A $\beta$ aggregates in general consist of soluble, dispersible, membrane-associated and plaque-associated forms in p-preAD as well as symAD cases [1]. This means that $\mathrm{A} \beta$ aggregates are theoretically capable of interacting with proteins of all fractions even in the p-preAD stage. The occurrence of $A \beta$ triggered changes in vesicle endocytosis-related processes is supported by previously reported findings that protein aggregates, including $A \beta$, can alter endocytosis $[65,66]$. Vesicle endocytosis and the secretory pathway were over-represented among early-responding and gradually-changing proteins, which were associated with the presence of $\mathrm{A} \beta$. However, they were less strongly correlated with the local $A \beta$ plaque load, the $A \beta$ phases and other AD-related neuropathological parameters. Accordingly, it is tempting to speculate that the pure presence of pathological $A \beta$ aggregates even in a low concentration is the driving force behind the identified preclinical proteome alterations in the neocortex.

\section{S2.2 Specific protein changes and their possible involvement in the pathogenesis of AD}

Half of the early-responding proteins, including AP1B1_HUMAN and SH3G2_HUMAN, are involved in vesicle endocytosis and the secretory pathway (Table S5a), and showed decreased levels (Figure S2). This alteration probably occurred in neurons/neuropil where the respective proteins have been mapped [31]. The decrease in the abundance of gradually-changing proteins 
associated with vesicle endocytosis and the secretory pathway (CLH1_HUMAN, CLCB_HUMAN, AP2A1_HUMAN, and AP2A2_HUMAN) further supports the critical involvement of these pathways in AD. These proteins are present in neurons/neuropil [31], and are required for normal brain function. However, they decreased in the dispersible fraction. On the other hand, CALM1_HUMAN, which plays an important role in calcium signaling, was elevated in p-preAD. Whether this is a reactive phenomenon, a pathology driving phenomenon, or a possible sign of resilience, still needs to be clarified.

Furthermore, a large number of the gradually-changing and late-responding proteins were elevated in $\mathrm{AD}$. Whether they reflect reactive/protective changes or a pathological accumulation of proteins such as A4_HUMAN (A $\beta / A P P)$ and TAU_HUMAN (tau), cannot be predicted in this study. The increase in EAA2_HUMAN (EAAT2) in the SDS fraction of symAD cases could reflect the previously described aberrant neuronal expression of this receptor protein in p-tau positive neurons in symAD cases [67]. Reactive astrogliosis reported in symAD patients $[68,69]$ may be associated with increased VIME_HUMAN (vimentin) levels, known to be expressed in reactive astrocytes in symAD [70]. Given the reduced abundance of early-responding and gradually-changing proteins that were associated with “MHC class II antigen presentation” (GO: 0019886 and R-HSA-2132295) (AP2A2_HUMAN, AP1B1_HUMAN, CLH1_HUMAN, AP2A1_HUMAN, and SH3G2_HUMAN), we speculate that microglial cells in p-preAD and AD show an impairment in MHC class II-related antigen presentation due to alterations in $\mathrm{AD}$-related proteins involved in vesicle endocytosis and secretory processes essential for antigen presentation. Whether the reduction in MHC class II antigen presentation-related proteins is a consequence or cause of the microglial cell activation in $\mathrm{AD}[32,71,72]$, cannot be answered by the data presented here. The future analysis of APP and tau transgenic mouse models will help to further clarify this question. 
Endophilin-A1 is implicated in the synaptic vesicle endocytosis [73, 74]. Moreover, RAB3A_HUMAN, CLCB_HUMAN, CLH1_HUMAN, AP2A1_HUMAN and AP2A2_HUMAN are involved in "synaptic vesicle cycle" (KEGG: hsa04721) $[75,76]$ and CALM1_HUMAN (calmodulin-1) plays a role in synaptic potential regulation [77]. This suggests that alterations of synaptic function in $\mathrm{AD}[78,79]$ are represented by the level changes of these proteins. WGCNA of our data also pointed to the "synaptic vesicle cycle" (KEGG: hsa04721), "synapse” (GO: 0045202), "synaptic vesicle" (GO: 0008021) and "synaptosome" as being involved in the pathogenesis of $\mathrm{AD}$, in line with previous reports of synaptic loss in $\mathrm{AD}$ [79]. Given that two of the involved proteins are early-responding proteins, we speculate that alterations in synapse function represent one of the earliest biochemical correlatives of AD. There is emerging evidence that $\mathrm{A} \beta$ accelerates $\mathrm{p}$-tau pathology with the cellular prion protein being involved [80, 81], and both, $\mathrm{A} \beta$ and $\mathrm{p}$-tau, bind to prion protein in symAD cases [80]. In this stage of $\mathrm{AD}$, prion protein levels in the brain were reduced as seen here and as previously shown by others [82-84]. Moreover, prion protein expressing neurons in the brain were decreased in symAD [80]. Thus, it is tempting to speculate that binding of $A \beta$ and $p$-tau to prion protein reduces the neuronal prion protein expression in the brain. Interestingly, $\operatorname{PrP}^{\mathrm{C}}$ endocytosis includes clathrin-mediated mechanisms [85]. Therefore, it may be tempting to speculate that binding of $\mathrm{A} \beta$ and/or $p$-tau to $\operatorname{PrP}^{\mathrm{C}}$ is an early phenomenon in $\mathrm{AD}$ pathogenesis that has impact on the availability of this endocytosis mechanism. Recently published proximity ligation assay findings showing proximity of $\mathrm{A} \beta$ and $\mathrm{PrP}^{\mathrm{C}}$ as well as $\mathrm{p}$-tau and $\operatorname{PrP}^{\mathrm{C}}$ [80] may support this hypothesis.

Finally, the increasing levels of FIBG_HUMAN (fibrinogen) in the dispersible fraction correlated with the CAA-related parameters pointing to a CAA-related leakage of the blood brain barrier in AD as previously suggested [86]. 


\section{S2.3 Preclinical AD and resilience}

Whether cases classified as p-preAD would have converted into symAD cannot be determined in autopsy tissue. Thus, the p-preAD group may also include cases that were in a status of resilience. However, a stepwise evolution of $A \beta$ and p-tau pathology as represented by the $A \beta$ phases and the Braak NFT-stages in the human brain $[2,9]$ have also been observed in animal models of $A \beta$ [87] and tau pathology [88], and confirmed in the human brain by repetitive PET imaging [89-91]. Accordingly, the sequential proteomic changes observed in our study presumably reflect changes occurring on the way to the onset of symAD. The reduction of vesicle endocytosis and the secretory pathway-related proteins in p-preAD cases strongly argues in favor of a degenerative phenomenon. Likewise, the proteome stages describing the sequential occurrence of protein level changes in the brain support the hypothesis that p-preAD represents an earlier stage of symAD. However, a strong argument in favor of resilience factors being active in the p-preAD stage is the presence of two early-responding proteins, e.g. RL31_HUMAN, that show a second late-responding effect in the opposite direction (Figure S2s'). Another early-responding protein, CALM1_HUMAN, is significantly increased in ppreAD and comes back to normal levels in symAD (Figure S2i'"). The late-responding protein UBA1_HUMAN is another example showing also a trend towards an opposing regulation in ppreAD and symAD (Figure S2t). Accordingly, our data suggest that degenerative and possible resilience phenomena are presumably present in parallel in p-preAD. To which degree resilience factors modify the course of AD needs to be clarified in the future, maybe by cell culture or animal experiments in which potential resilience factors are modulated. Strengthening resilience by targeting related proteins to postpone the onset of symAD may represent a novel therapeutic approach. 


\section{S2.4 Methodological impact on the detection of proteome changes}

Our results with 1449 identified proteins differ from other studies that identified, e.g. 3334 proteins [32] due to methodological differences. This also influenced the number of proteins detected to be associated with $\mathrm{AD}$ which is 50 in our study but $20-254$ proteins/model in the study by Johnson et al. [32]. We performed the peptide search in the Swiss-Prot database, which is smaller than the Uniprot database (Swiss-Prot + TrEMBL) that was used by other authors $[32,33,35,36,39]$, and includes only reviewed entries. We also set the cutoff for reporting detected proteins more stringent than other authors (Suppl. Methods). Compared to Johnson et al. [32] who set the false discovery rate (FDR) for peptide spectral matches at $1 \%$, our FDR was $0.02 \%$ for soluble and dispersible fractions, $0.03 \%$ for the SDS fraction, and $0.04 \%$ for the FA fraction. Moreover, we determined the protein identification probability. If the maximum protein identification probability of a given protein in all samples belonging to the same fraction was less than $100 \%$, we excluded the protein from the list, which means it was not even counted as background. This stringent setting for reducing the likelihood of false positive findings had impact on the number of proteins we reported. E.g., some microglia and astroglia-related proteins were not detected here.

Importantly, our cohort covered nonAD control, p-preAD and symAD cases, in which some AD-related proteins may not be detectable in half of the cases because of disease-related reasons. Moreover, we used nonparametric statistics as the first step in our univariate statistical analysis, which is very robust and allows correction for multiple testing. Furthermore, to avoid false positive findings, we considered only those differences as relevant when they were observed in age and sex controlled statistical models after correction for multiple testing.

To overcome possible statistical limitations of our univariate approach, we also applied a multivariate spectral analysis, i.e. WGCNA. The advantage of WGCNA is that this approach is systematic and takes the entire proteome into account. It determines protein modules and 
correlates them with clinical/pathological parameters. However, it also has disadvantages. In our case, it does not include some of the proteins which significantly changed among nonAD, p-preAD and symAD cases in the AD-associated modules, for example, CLH1_HUMAN and CLCB_HUMAN from dispersible fraction (Table S7 and S8), which can be identified by the univariate approach. However, these proteins observed in other fractions contributed to the modules associated with pathological parameters. This suggested that WGCNA adds significant information about the proteome but does not replace proper univariate analysis. Stages describing the sequential involvement of proteins as indicated by level changes were not found with WGCNA, only with the univariate approach.

Our protein extraction and fractionation protocol probably also limited the yield, although at the same time, it provided topological/solubility information. Moreover, the label-free shotgun proteomic approach did not distinguish between APP and A $\beta$ after trypsin digestion of the proteins, although immunohistochemistry and quantitative western blot analysis confirmed the increase of $\mathrm{A} \beta$ pathology in the frontal cortex of p-preAD and symAD cases in the soluble, dispersible, SDS, and FA fraction [1]. Twenty-one of the 53 cases studied here were also included in the analysis of Rijal Upadhaya et al. [1].

\section{S2.5 Limitations}

The analysis of only occipital/frontal neocortex can be considered as a limitation. Our analysis must be interpreted in the light of the region-specific development of $A \beta$ plaques and $\mathrm{p}$-tau pathology. In occipital/frontal neocortex, $\mathrm{A} \beta$ plaques appear first in p-preAD cases and are followed by p-tau pathology in symAD patients. Accordingly, in our study, the changes in levels of early-responding proteins in occipital/frontal cortex appear to be mainly related to $\mathrm{A} \beta$ pathology, whereas the second stage of proteome changes is associated with the full spectrum 
of $A \beta$ and p-tau pathology. This sequence of events is different from that in the brain stem and the transentorhinal/entorhinal cortex, where p-tau pathology precedes the development of $A \beta$ plaques $[81,92]$.

A second limitation is that we studied only 53 cases. However, many other mass spectrometry studies did not include more cases $[36,38,93]$ and our stringent statistical approach discussed in 4.5 reduced the chance of false positive findings [32].

The younger mean age of non $\mathrm{AD}$ cases may be considered as a third limitation. However, given the age-related increase of the prevalence of AD neuropathology, cases fulfilling the non $\mathrm{AD}$ criteria (no amyloid plaques) are rare in individuals over 70 years of age whereas p-preAD and symAD cases prevail in this age group [92]. To control our statistical analysis for this age/sexrelated effect, we used age and sex as additional covariates in the regression analysis. Likewise, we controlled our models for the post-mortem interval to reduce the bias induced by this parameter.

The cross-sectional nature of this study is another limitation. Although we provide cross sectional data, it is essential to mention that transgenic mouse models [87, 88] as well as amyloid and tau-PET studies showed a progression of A $\beta$ and p-tau pathology over time [87, 90]. This strongly supports that our study design involving cases with different stages of AD neuropathological changes allows conclusions on the development of the disease.

Finally, this type of biochemical analysis of post-mortem human brain tissue cannot be carried out in living patients at multiple time points for ethical reasons because multiple brain biopsies would be required to follow the proteome changes over time. Mouse models for AD pathology are also suboptimal for this purpose because $\mathrm{AD}$ is a complex disease which is not covered in all aspects by these models. Thus, autopsy tissue is the best material that we have available for this kind of studies. 


\section{S3 Supplementary figures:}

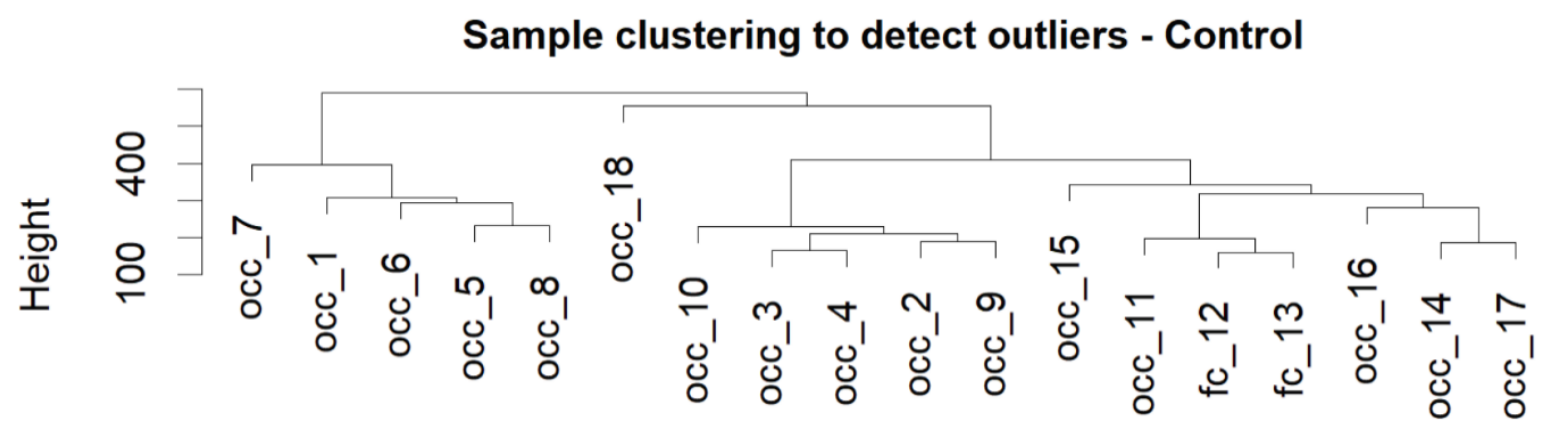

Figure S1. Unweighted sample clustering among control cases. No outliers were identified indicating no significant differences in the neocortical protein expression patterns between frontal (Brodmann area 6) and occipital (Brodmann areas 17-19) cortex samples. occ $=$ occipital cortex, $\mathrm{fc}=$ frontal cortex. 


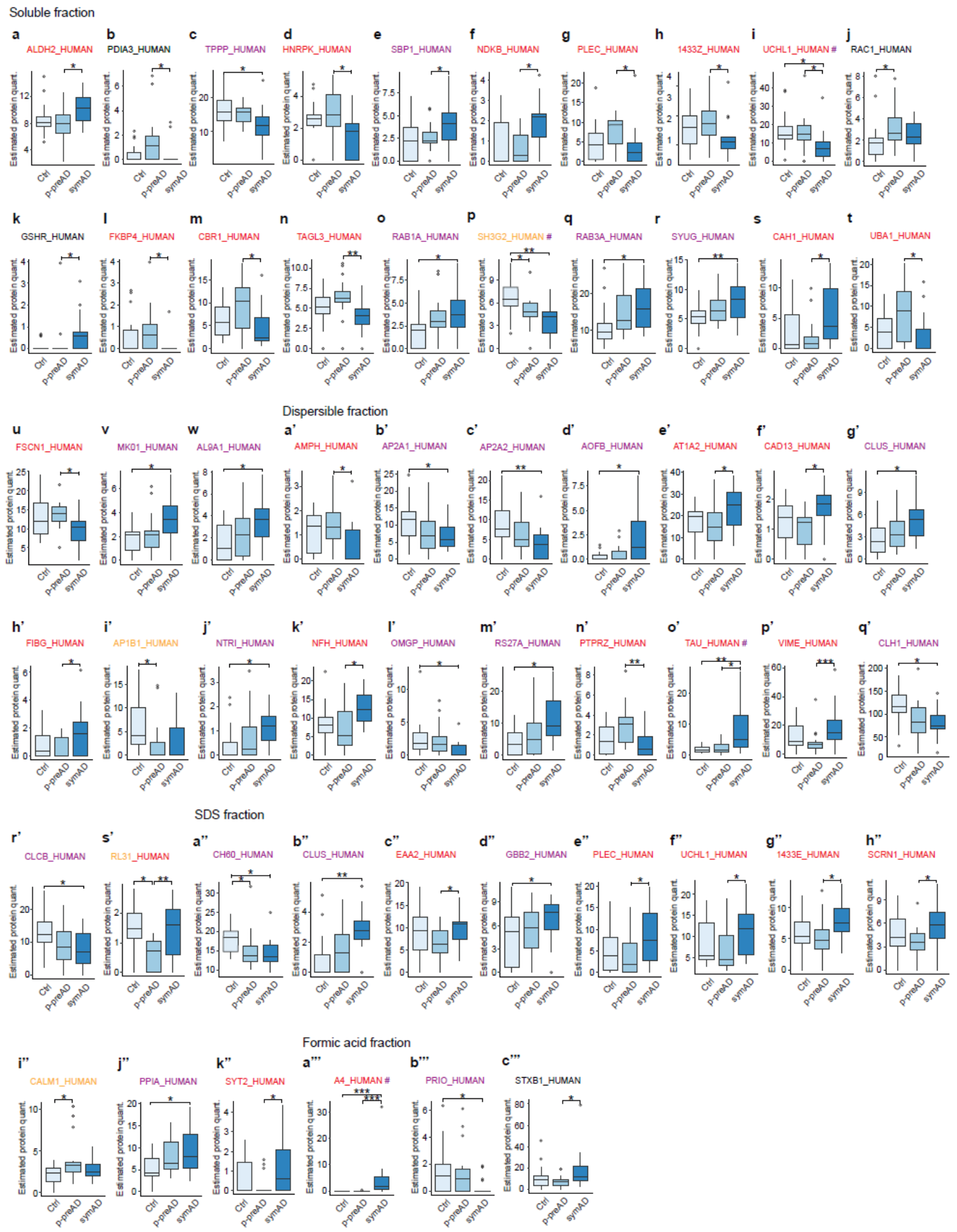

Figure S2. Fifty-three proteins (regardless of fraction) with significant changes in the protein levels among nonAD control, p-preAD and symAD cases. The box plot diagrams depict individual protein levels in a given fraction represented by the quantitative value from 
normalized spectrum counts among control (nonAD), p-preAD and symAD cases: a- w. soluble fraction; a'- s'. dispersible fraction; a"'- k"'.SDS fraction; a"'- c'"'. Formic acid fraction. The proteins belong to early-/late-responding or gradually-changing protein groups. Earlyresponding proteins are highlighted in yellow, late-responding proteins in red, and graduallychanging proteins in violet. Note the intermediate levels in p-preAD cases observed for gradually-changing proteins when comparing non $\mathrm{AD}$, p-pre $\mathrm{AD}$, and symAD cases. Four proteins that gradually changed between nonAD controls and symAD also met the criteria for early- or late-responding proteins and are marked by \#. Four protein (black) were not classified as early-, late-responding, or gradually-changing protein because regression analysis controlled for age and sex did not confirm the results from Kruskal-Wallis $\mathrm{H}$ test. Two-tailed KruskalWallis $\mathrm{H}$ test with multiple comparison of mean ranks are used, $* \mathrm{p}<0.05, * * \mathrm{p}<0.01, * * * \mathrm{p}$ $<0.001$. Center line, median; box limits, upper and lower quartiles; whiskers, $1.5 \mathrm{x}$ interquartile range; circle, outliers. n: 18 non $\mathrm{AD}, 18$ p-pre $\mathrm{AD}, 17$ symAD cases. 


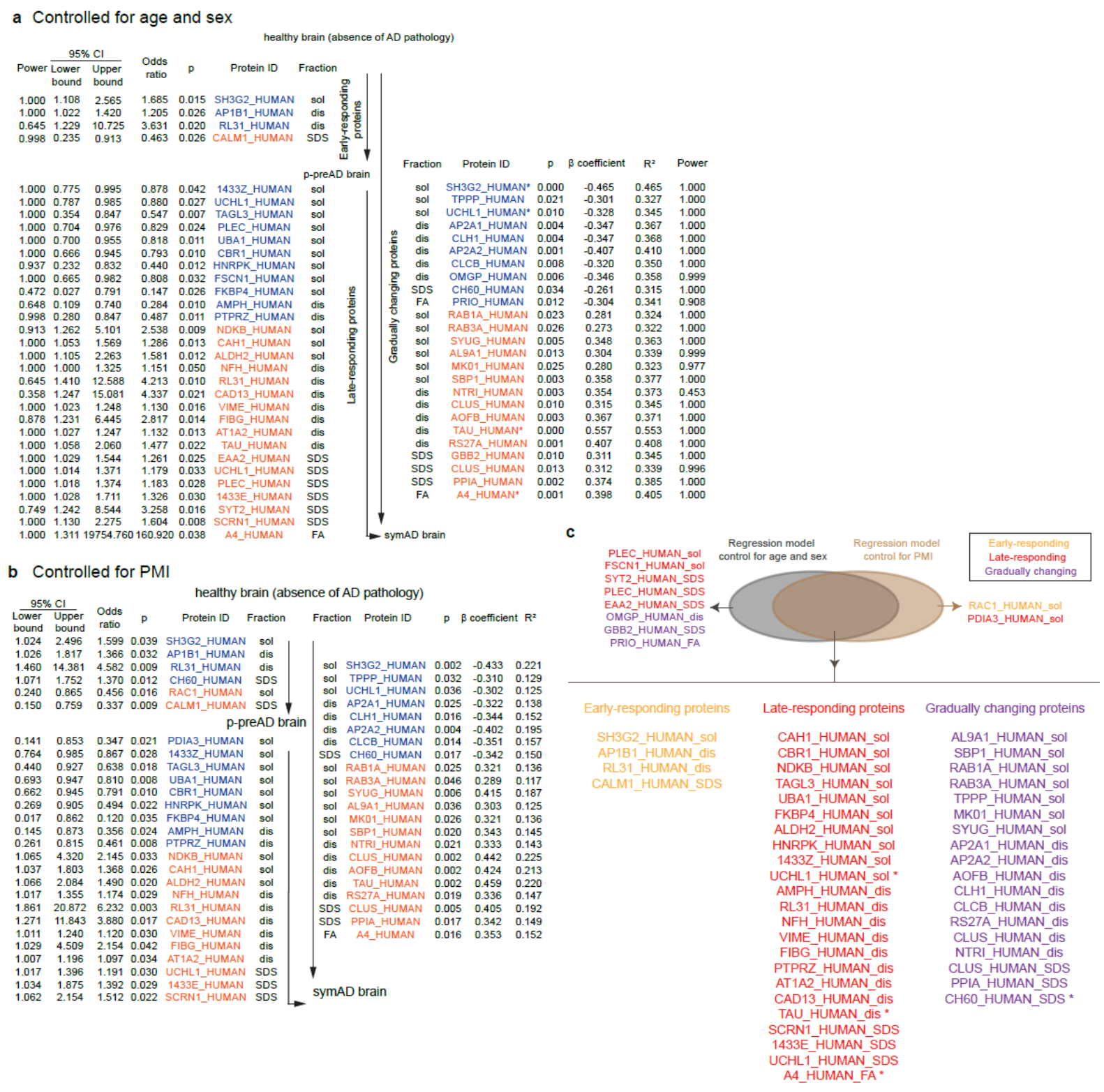

Figure S3. a, b. The abundance of proteins changed sequentially during the progression of Alzheimer's disease and allowed the distinction of three different groups of proteins. Proteins that significantly changed between control and p-preAD cases (upper left $=$ early-responding proteins), between $\mathrm{p}$-preAD and symAD (lower left = late-responding proteins), and between controls and symAD (right $=$ gradually-changing, including five proteins also identified as early- or late-responding proteins $(*)$ ). Multinomial logistic regression (for early- and lateresponding proteins, p-preAD as a reference group) and linear regression (for graduallychanging proteins) were performed with the diagnosis scores indicating the clinical- 
pathological steps of $\mathrm{AD}$ development (control $=0, \mathrm{p}-\mathrm{pre} \mathrm{AD}=1$, and sym $\mathrm{AD}=2$ ) as dependent variable, and with protein quantification, a. age and sex or b. PMI as independent variables. Proteins increasing in abundance in p-preAD or symAD were indicated in red, and those decreasing were marked in blue. Odds ratio and 95\% confidence interval were indicated for multinomial logistic regression analysis, $\beta$-coefficient and $\mathrm{r}^{2}$ were indicated for linear regression analysis, whereas $\mathrm{p}$ value and statistical power were indicated for both analyses. We showed the results of the power analysis only in the event that the levels of early- or lateresponding and gradually-changing proteins exhibited significant changes in age and sex controlled regression models (a). c. A comparison of the protein lists from multinominal logistic and linear regression analyses controlled for either PMI or for age and sex. Protein names, the corresponding fractions, and the protein group were indicated. * indicates that the respective protein belonged to more than one protein group in the regression models we used. RL31_HUMAN_dis was an early- and late-responding protein in both age-sex controlled and PMI controlled model.CH60_HUMAN_SDS was a gradually-changing protein in the age- and sex-controlled model and an early-responding protein in the PMI-controlled model, while TAU_HUMAN_dis, A4_HUMAN_FA and UCHL1_HUMAN_sol were late-responding proteins in the age- and sex-controlled model but gradually-changing proteins in the respective PMI-controlled model. n: 18 nonAD, 18 p-preAD, 17 symAD cases. 
a

Module-trait relationships

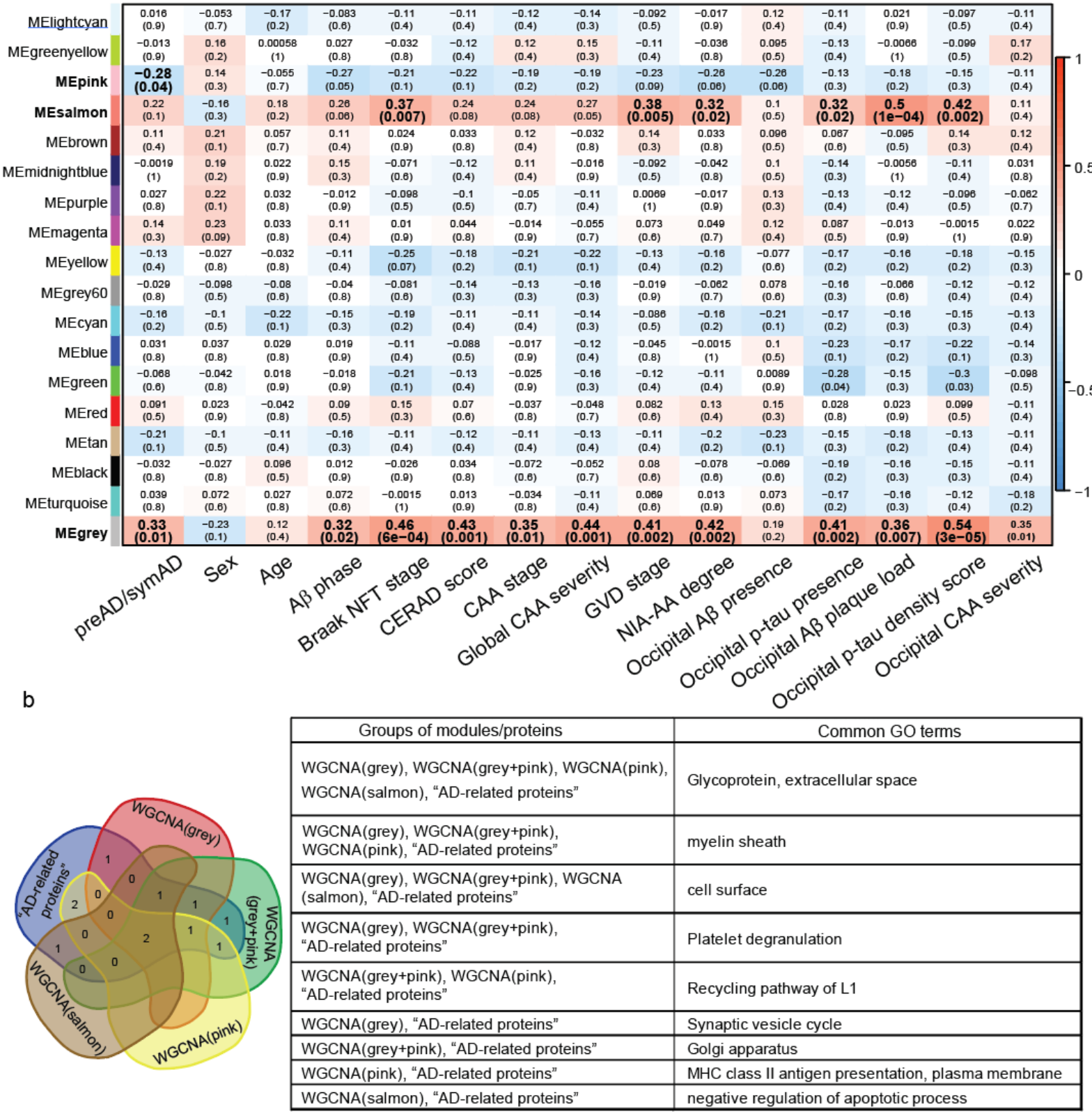

Figure S4. WGCNA analysis. a. Three modules that were received from WGCNA analysis (grey, pink, salmon) showed correlations with pathological parameters in the table exhibiting the module-traits relationships. b. Comparison of GO enrichment analysis between proteins from WGCNA-identified AD-related modules and the AD-related proteins received from univariate statistical analysis. The GO terms that were over-represented in both approaches were shown as "Common GO terms". 
a

Module-trait relationships

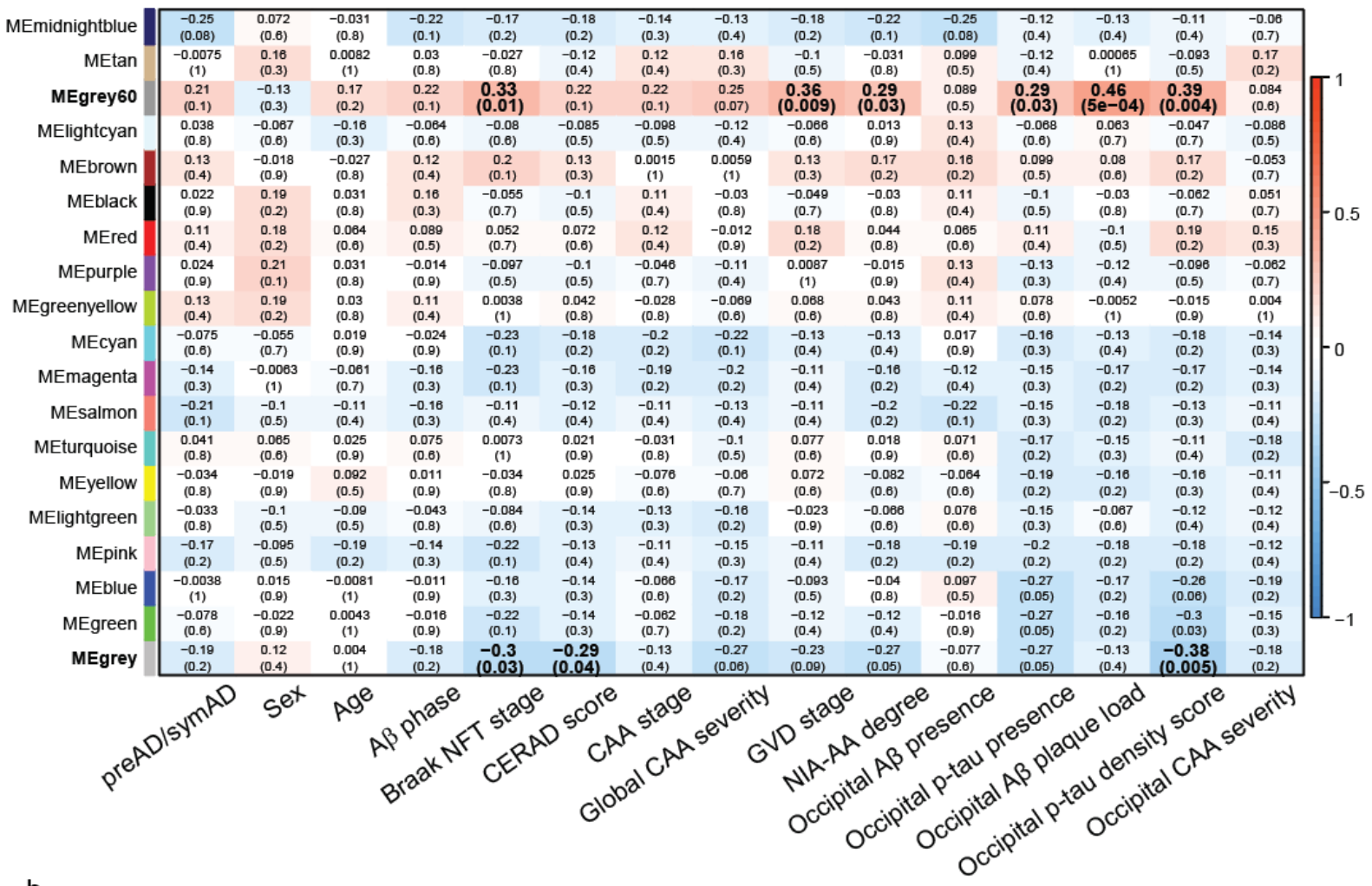

b

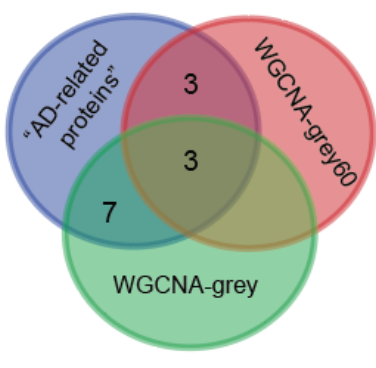

\begin{tabular}{|c|l|}
\hline Groups of modules/proteins & \multicolumn{1}{|c|}{ Common GO terms } \\
\hline $\begin{array}{c}\text { WGCNA-grey } \\
\text { WGCNA-grey60 } \\
\text { "AD-related proteins" }\end{array}$ & cell surface, Glycoprotein, extracellular space \\
\hline WGCNA-grey60 & $\begin{array}{l}\text { negative regulation of apoptotic process, Caspase- } \\
\text { mediated cleavage of cytoskeletal, proteins focal } \\
\text { adhesion }\end{array}$ \\
\hline WG-related proteins" & $\begin{array}{l}\text { Platelet degranulation, Lysosome Vesicle } \\
\text { Biogenesis, vesicle-mediated transport, clathrin- } \\
\text { coated endocytic vesicle membrane, Lysosome, } \\
\text { Golgi apparatus, myelin sheath }\end{array}$ \\
\hline "AD-related proteins" & \\
\hline
\end{tabular}

Figure S5. Second WGCNA analysis using a pre-filtered dataset. To focus on proteins that show no collinearity effects for age and sex, we excluded all proteins of which the abundances were significantly associated with age and/or sex in linear regression models from the analysis.

a. Two modules received from this second WGCNA analysis (grey, grey60) showed correlations with pathological parameters in the table exhibiting the module-traits relationships.

b. Comparison of GO enrichment analysis between proteins from the second WGCNAidentified AD-related modules and the AD-related proteins received from univariate statistical analysis. The GO terms that were over-represented in both approaches were shown as "Common GO terms". 


\section{S4 Legends - Supplementary tables:}

Table S1. List of cases with neuropathological diagnosis. Abbreviations: $y=$ age in years; $f=$ female; $m=$ male; $A \beta$ phase $=$ phase of $A \beta$-plaque deposition [2]; Braak NFT stage $=$ stage of neurofibrillary tangle pathology [9]; CERAD = consortium to establish a registry for AD [10]; NIA-AA $=$ The National Institute of Aging-Alzheimer Association; CAA severity = severity degree of cerebral amyloid angiopathy [12]; CAA stage: stage of neuroanatomical distribution of CAA [11]; GVD stage = stage of neuroanatomical distribution of granulovacuolar degeneration [13]; $\mathrm{PMI}=$ post-mortem interval in hours; $\mathrm{CDR}=$ the clinical dementia rating [3]; * this case classified to have mild cognitive impairment showed only very mild, negligible deficits in memory, difficult problem solving and community affairs and needed reminders for personal care not fullfilling any signs of dementia; n.d. = not determined. None of the AD cases included in this study had a known family history of Alzheimer's disease.

Table S2. The maximum protein confidence for the proteins included in the quantitative analysis.

Table S3. List of significantly changed proteins (multiple comparisons p values (2-tailed); Kruskal-Wallis $\mathrm{H}$ test with multiple comparisons of mean ranks for all groups). n: 18 nonAD, 18 p-preAD, 17 symAD cases. The data for cortical immunohistochemical pattern and subcellular localization are cited from the human protein atlas (https://www.proteinatlas.org/) or literature [67, 70, 94-96]. 
Table S4. Binary logistic regression model fit for fraction-shifting proteins. a. Controlled for age and sex. b. Controlled for PMI. a, b: n: 36 nonAD and p-preAD cases vs. 17 symAD cases.

Table S5. Gene ontology (GO) over-representation analysis. a. GO terms over-represented in early-, late-responding and gradually-changing proteins (results from univariate approach). b. GO terms over-represented by AD-related modules after WGCNA analysis including all identified proteins. c. GO terms over-represented by AD-related modules after WGCNA analysis including only proteins that do not show collinearity for age and/or sex.

Table S6. Partial correlation with AD neuropathological parameters and local AD lesion measurements. a. Proteins significantly correlating with AD diagnosis score controlled for age and sex. b. Proteins significantly correlating with AD diagnosis score controlled for PMI.

Table S7. WGCNA analysis including all proteins. Module Memberships of 3104 proteins (with fraction information) quantified in 53 case samples after network connectivity outlier removal. Gene Significance (GS) is the correlation between the gene and the trait. For each module, a quantitative measure of module membership (MM) is the correlation of the module eigengene and the gene expression profile.

Figure S8. WGCNA analysis including only proteins that do not show collinearity for age and/or sex. Module Memberships of 2924 proteins (with fraction information) quantified in 53 case samples after network connectivity outlier removal. Gene Significance (GS) is the correlation between the gene and the trait. For each module, a quantitative measure of module membership (MM) is the correlation of the module eigengene and the gene expression profile. 
Table S9. Comparison between the list of early-, late-responding and gradually-changing proteins identified in the current study and those previously published by other authors [32-42]. Overlapping proteins were highlighted in yellow.

Table S10. Proteins identified only in our study showing differential levels across nonAD, ppreAD and symAD. 


\section{S5 References to supplement}

[1] Rijal Upadhaya A, Kosterin I, Kumar S, Von Arnim C, Yamaguchi H, Fändrich M, et al. Biochemical stages of amyloid $\beta$-peptide aggregation and accumulation in the human brain and their association with symptomatic and pathologically-preclinical Alzheimer's disease. Brain. 2014;137:887-903.

[2] Thal DR, Rüb U, Orantes M, Braak H. Phases of Abeta-deposition in the human brain and its relevance for the development of AD. Neurology. 2002;58:1791-800.

[3] Hughes CP, Berg L, Danziger WL, Coben LA, Martin RL. A new clinical scale for the staging of dementia. Br J Psychiatry. 1982;140:566-72.

[4] Hyman BT, Phelps CH, Beach TG, Bigio EH, Cairns NJ, Carrillo MC, et al. National Institute on Aging-Alzheimer's Association guidelines for the neuropathologic assessment of Alzheimer's disease. Alzheimers Dement. 2012;8:1-13.

[5] Sperling RA, Aisen PS, Beckett LA, Bennett DA, Craft S, Fagan AM, et al. Toward defining the preclinical stages of Alzheimer's disease: recommendations from the National Institute on AgingAlzheimer's Association workgroups on diagnostic guidelines for Alzheimer's disease. Alzheimer's \& dementia : the journal of the Alzheimer's Association. 2011;7:280-92.

[6] Jack CR, Jr., Bennett DA, Blennow K, Carrillo MC, Dunn B, Haeberlein SB, et al. NIA-AA Research Framework: Toward a biological definition of Alzheimer's disease. Alzheimers Dement. 2018;14:53562.

[7] Crary JF, Trojanowski JQ, Schneider JA, Abisambra JF, Abner EL, Alafuzoff I, et al. Primary agerelated tauopathy (PART): a common pathology associated with human aging. Acta Neuropathol. 2014;128:755-66.

[8] Braak H, Alafuzoff I, Arzberger T, Kretzschmar H, Del Tredici K. Staging of Alzheimer diseaseassociated neurofibrillary pathology using paraffin sections and immunocytochemistry. Acta Neuropathol. 2006;112:389-404.

[9] Braak H, Braak E. Neuropathological stageing of Alzheimer-related changes. Acta Neuropathol. 1991;82:239-59.

[10] Mirra SS, Heyman A, McKeel D, Sumi SM, Crain BJ, Brownlee LM, et al. The Consortium to Establish a Registry for Alzheimer's Disease (CERAD). Part II. Standardization of the neuropathologic assessment of Alzheimer's disease. Neurology. 1991;41:479-86.

[11] Thal DR, Ghebremedhin E, Orantes M, Wiestler OD. Vascular pathology in Alzheimer's disease: Correlation of cerebral amyloid angiopathy and arteriosclerosis / lipohyalinosis with cognitive decline. J Neuropathol Exp Neurol. 2003;62:1287-301.

[12] Vonsattel JP, Myers RH, Hedley-Whyte ET, Ropper AH, Bird ED, Richardson EP, Jr. Cerebral amyloid angiopathy without and with cerebral hemorrhages: a comparative histological study. Ann Neurol. 1991;30:637-49.

[13] Thal DR, Del Tredici K, Ludolph AC, Hoozemans JJ, Rozemuller AJ, Braak H, et al. Stages of granulovacuolar degeneration: their relation to Alzheimer's disease and chronic stress response. Acta Neuropathol. 2011;122:577-89.

[14] Kadokura A, Yamazaki T, Kakuda S, Makioka K, Lemere CA, Fujita Y, et al. Phosphorylationdependent TDP-43 antibody detects intraneuronal dot-like structures showing morphological characters of granulovacuolar degeneration. Neuroscience letters. 2009;463:87-92.

[15] Rijal Upadhaya A, Capetillo-Zarate E, Kosterin I, Abramowski D, Kumar S, Yamaguchi H, et al. Dispersible amyloid $\beta$-protein oligomers, protofibrils, and fibrils represent diffusible but not soluble aggregates: Their role in neurodegeneration in amyloid precursor protein (APP) transgenic mice. Neurobiol Aging. 2012;33:2641-60.

[16] Alafuzoff I, Arzberger T, Al-Sarraj S, Bodi I, Bogdanovic N, Braak H, et al. Staging of neurofibrillary pathology in Alzheimer's disease. A study of the BrainNet Europe Consortium. . Brain Pathol. 2008;18:484-96. 
[17] Langfelder P, Horvath S. WGCNA: an R package for weighted correlation network analysis. BMC Bioinformatics. 2008;9:559.

[18] McDonald JM, Cairns NJ, Taylor-Reinwald L, Holtzman D, Walsh DM. The levels of water-soluble and triton-soluble Abeta are increased in Alzheimer's disease brain. Brain Res. 2012;1450:138-47.

[19] Kall L, Storey JD, MacCoss MJ, Noble WS. Assigning significance to peptides identified by tandem mass spectrometry using decoy databases. J Proteome Res. 2008;7:29-34.

[20] Huang da W, Sherman BT, Lempicki RA. Systematic and integrative analysis of large gene lists using DAVID bioinformatics resources. Nat Protoc. 2009;4:44-57.

[21] Huang da W, Sherman BT, Lempicki RA. Bioinformatics enrichment tools: paths toward the comprehensive functional analysis of large gene lists. Nucleic Acids Res. 2009;37:1-13.

[22] Chartier-Harlin MC, Crawford F, Houlden H, Warren A, Hughes D, Fidani L, et al. Early-onset Alzheimer's disease caused by mutations at codon 717 of the beta-amyloid precursor protein gene. Nature. 1991;353:844-6.

[23] Goate A, Chartier-Harlin MC, Mullan M, Brown J, Crawford F, Fidani L, et al. Segregation of a missense mutation in the amyloid precursor protein gene with familial Alzheimer's disease. Nature. 1991;349:704-6.

[24] St George-Hyslop PH, Tanzi RE, Polinsky RJ, Haines JL, Nee L, Watkins PC, et al. The genetic defect causing familial Alzheimer's disease maps on chromosome 21. Science. 1987;235:885-90.

[25] Rogaev El, Sherrington R, Rogaeva EA, Levesque G, Ikeda M, Liang Y, et al. Familial Alzheimer's disease in kindreds with missense mutations in a gene on chromosome 1 related to the Alzheimer's disease type 3 gene. Nature. 1995;376:775-8.

[26] St George-Hyslop P, Haines J, Rogaev E, Mortilla M, Vaula G, Pericak-Vance M, et al. Genetic evidence for a novel familial Alzheimer's disease locus on chromosome 14. Nat Genet. 1992;2:330-4.

[27] Cuyvers E, Sleegers K. Genetic variations underlying Alzheimer's disease: evidence from genomewide association studies and beyond. Lancet Neurol. 2016;15:857-68.

[28] de Rojas I, Moreno-Grau S, Tesi N, Grenier-Boley B, Andrade V, Jansen I, et al. Common variants in Alzheimer's disease: Novel association of six genetic variants with AD and risk stratification by polygenic risk scores. medRxiv. 2020:19012021.

[29] Kunkle BW, Grenier-Boley B, Sims R, Bis JC, Damotte V, Naj AC, et al. Genetic meta-analysis of diagnosed Alzheimer's disease identifies new risk loci and implicates Abeta, tau, immunity and lipid processing. Nat Genet. 2019;51:414-30.

[30] Szklarczyk D, Gable AL, Lyon D, Junge A, Wyder S, Huerta-Cepas J, et al. STRING v11: proteinprotein association networks with increased coverage, supporting functional discovery in genomewide experimental datasets. Nucleic Acids Res. 2019;47:D607-D13.

[31] Uhlen M, Fagerberg L, Hallstrom BM, Lindskog C, Oksvold P, Mardinoglu A, et al. Proteomics. Tissue-based map of the human proteome. Science. 2015;347:1260419.

[32] Johnson ECB, Dammer EB, Duong DM, Ping L, Zhou M, Yin L, et al. Large-scale proteomic analysis of Alzheimer's disease brain and cerebrospinal fluid reveals early changes in energy metabolism associated with microglia and astrocyte activation. Nat Med. 2020.

[33] Bai B, Wang X, Li Y, Chen PC, Yu K, Dey KK, et al. Deep Multilayer Brain Proteomics Identifies Molecular Networks in Alzheimer's Disease Progression. Neuron. 2020;106:700.

[34] Donovan LE, Higginbotham L, Dammer EB, Gearing M, Rees HD, Xia Q, et al. Analysis of a membrane-enriched proteome from postmortem human brain tissue in Alzheimer's disease. Proteomics Clin Appl. 2012;6:201-11.

[35] Seyfried NT, Dammer EB, Swarup V, Nandakumar D, Duong DM, Yin L, et al. A Multi-network Approach Identifies Protein-Specific Co-expression in Asymptomatic and Symptomatic Alzheimer's Disease. Cell Syst. 2017;4:60-72 e4.

[36] Hondius DC, van Nierop P, Li KW, Hoozemans JJ, van der Schors RC, van Haastert ES, et al. Profiling the human hippocampal proteome at all pathologic stages of Alzheimer's disease.

Alzheimers Dement. 2016;12:654-68. 
[37] Mendonca CF, Kuras M, Nogueira FCS, Pla I, Hortobagyi T, Csiba L, et al. Proteomic signatures of brain regions affected by tau pathology in early and late stages of Alzheimer's disease. Neurobiol Dis. 2019;130:104509.

[38] Higginbotham L, Dammer EB, Duong DM, Modeste E, Montine TJ, Lah JJ, et al. Network Analysis of a Membrane-Enriched Brain Proteome across Stages of Alzheimer's Disease. Proteomes. 2019;7.

[39] McKetney J, Runde RM, Hebert AS, Salamat S, Roy S, Coon JJ. Proteomic Atlas of the Human Brain in Alzheimer's Disease. J Proteome Res. 2019;18:1380-91.

[40] Andreev VP, Petyuk VA, Brewer HM, Karpievitch YV, Xie F, Clarke J, et al. Label-free quantitative LC-MS proteomics of Alzheimer's disease and normally aged human brains. J Proteome Res.

2012;11:3053-67.

[41] Musunuri S, Wetterhall M, Ingelsson M, Lannfelt L, Artemenko K, Bergquist J, et al.

Quantification of the brain proteome in Alzheimer's disease using multiplexed mass spectrometry. J

Proteome Res. 2014;13:2056-68.

[42] Xu J, Patassini S, Rustogi N, Riba-Garcia I, Hale BD, Phillips AM, et al. Regional protein expression in human Alzheimer's brain correlates with disease severity. Commun Biol. 2019;2:43.

[43] Yao L, Sakaba T. Activity-dependent modulation of endocytosis by calmodulin at a large central synapse. Proc Natl Acad Sci U S A. 2012;109:291-6.

[44] Soukup SF, Verstreken P. EndoA/Endophilin-A creates docking stations for autophagic proteins at synapses. Autophagy. 2017;13:971-2.

[45] Hartmann T, Bieger SC, Bruhl B, Tienari PJ, Ida N, Allsop D, et al. Distinct sites of intracellular production for Alzheimer's disease A beta40/42 amyloid peptides. Nat Med. 1997;3:1016-20.

[46] Capell A, Beher D, Prokop S, Steiner H, Kaether C, Shearman MS, et al. Gamma-secretase complex assembly within the early secretory pathway. J Biol Chem. 2005;280:6471-8.

[47] Runz H, Rietdorf J, Tomic I, de Bernard M, Beyreuther K, Pepperkok R, et al. Inhibition of intracellular cholesterol transport alters presenilin localization and amyloid precursor protein processing in neuronal cells. J Neurosci. 2002;22:1679-89.

[48] Haass C, Koo EH, Mellon A, Hung AY, Selkoe DJ. Targeting of cell-surface beta-amyloid precursor protein to lysosomes: alternative processing into amyloid-bearing fragments. Nature. 1992;357:5003.

[49] Selkoe DJ, Yamazaki T, Citron M, Podlisny MB, Koo EH, Teplow DB, et al. The role of APP processing and trafficking pathways in the formation of amyloid beta-protein. Ann N Y Acad Sci. 1996;777:57-64.

[50] Grbovic OM, Mathews PM, Jiang Y, Schmidt SD, Dinakar R, Summers-Terio NB, et al. Rab5stimulated up-regulation of the endocytic pathway increases intracellular beta-cleaved amyloid precursor protein carboxyl-terminal fragment levels and Abeta production. J Biol Chem.

2003;278:31261-8.

[51] Rajendran L, Honsho M, Zahn TR, Keller P, Geiger KD, Verkade P, et al. Alzheimer's disease betaamyloid peptides are released in association with exosomes. Proceedings of the National Academy of Sciences of the United States of America. 2006;103:11172-7.

[52] Rajendran L, Annaert W. Membrane trafficking pathways in Alzheimer's disease. Traffic. 2012;13:759-70.

[53] Takahashi RH, Milner TA, Li F, Nam EE, Edgar MA, Yamaguchi H, et al. Intraneuronal Alzheimer abeta42 accumulates in multivesicular bodies and is associated with synaptic pathology. Am J Pathol. 2002;161:1869-79.

[54] Trinczek B, Ebneth A, Mandelkow EM, Mandelkow E. Tau regulates the attachment/detachment but not the speed of motors in microtubule-dependent transport of single vesicles and organelles. J

Cell Sci. 1999;112 ( Pt 14):2355-67.

[55] Katsinelos T, Zeitler M, Dimou E, Karakatsani A, Muller HM, Nachman E, et al. Unconventional Secretion Mediates the Trans-cellular Spreading of Tau. Cell Rep. 2018;23:2039-55.

[56] Peng C, Trojanowski JQ, Lee VM. Protein transmission in neurodegenerative disease. Nat Rev Neurol. 2020;16:199-212. 
[57] Lasagna-Reeves CA, Castillo-Carranza DL, Sengupta U, Sarmiento J, Troncoso J, Jackson GR, et al. Identification of oligomers at early stages of tau aggregation in Alzheimer's disease. FASEB J.

2012;26:1946-59.

[58] Braak E, Braak H, Mandelkow EM. A sequence of cytoskeleton changes related to the formation of neurofibrillary tangles and neuropil threads. Acta Neuropathol. 1994;87:554-67.

[59] Thal DR, Rub U, Schultz C, Sassin I, Ghebremedhin E, Del Tredici K, et al. Sequence of Abetaprotein deposition in the human medial temporal lobe. J Neuropathol Exp Neurol. 2000;59:733-48.

[60] Guo JL, Lee VM. Cell-to-cell transmission of pathogenic proteins in neurodegenerative diseases. Nat Med. 2014;20:130-8.

[61] Calafate S, Buist A, Miskiewicz K, Vijayan V, Daneels G, de Strooper B, et al. Synaptic Contacts Enhance Cell-to-Cell Tau Pathology Propagation. Cell Rep. 2015;11:1176-83.

[62] Ruan Z, Pathak D, Venkatesan Kalavai S, Yoshii-Kitahara A, Muraoka S, Bhatt N, et al. Alzheimer's disease brain-derived extracellular vesicles spread tau pathology in interneurons. Brain. 2020.

[63] Pasternak SH, Callahan JW, Mahuran DJ. The role of the endosomal/lysosomal system in amyloid-beta production and the pathophysiology of Alzheimer's disease: reexamining the spatial paradox from a lysosomal perspective. J Alzheimers Dis. 2004;6:53-65.

[64] Almeida CG, Takahashi RH, Gouras GK. Beta-amyloid accumulation impairs multivesicular body sorting by inhibiting the ubiquitin-proteasome system. J Neurosci. 2006;26:4277-88.

[65] Jin S, Kedia N, Illes-Toth E, Haralampiev I, Prisner S, Herrmann A, et al. Amyloid-beta(1-42) Aggregation Initiates Its Cellular Uptake and Cytotoxicity. J Biol Chem. 2016;291:19590-606.

[66] Yu A, Shibata Y, Shah B, Calamini B, Lo DC, Morimoto RI. Protein aggregation can inhibit clathrinmediated endocytosis by chaperone competition. Proc Natl Acad Sci U S A. 2014;111:E1481-90.

[67] Thal DR. Excitatory amino acid transporter EAAT-2 in tangle-bearing neurons in Alzheimer's disease. Brain Pathol. 2002;12:405-11.

[68] Dickson DW, Farlo J, Davies P, Crystal H, Fuld P, Yen SH. Alzheimer's disease. A double-labeling immunohistochemical study of senile plaques. Am J Pathol. 1988;132:86-101.

[69] Thal DR. The role of astrocytes in amyloid beta-protein toxicity and clearance. Exp Neurol. 2012;236:1-5.

[70] Kamphuis W, Middeldorp J, Kooijman L, Sluijs JA, Kooi EJ, Moeton M, et al. Glial fibrillary acidic protein isoform expression in plaque related astrogliosis in Alzheimer's disease. Neurobiol Aging. 2014;35:492-510.

[71] McGeer PL, Walker DG, Akiyama H, Yasuhara O, McGeer EG. Involvement of microglia in Alzheimer's disease. Neuropathol Appl Neurobiol. 1994;20:191-2.

[72] Strauss S, Bauer J, Ganter U, Jonas U, Berger M, Volk B. Detection of interleukin-6 and alpha 2macroglobulin immunoreactivity in cortex and hippocampus of Alzheimer's disease patients. Lab Invest. 1992;66:223-30.

[73] Guichet A, Wucherpfennig T, Dudu V, Etter S, Wilsch-Brauniger M, Hellwig A, et al. Essential role of endophilin $A$ in synaptic vesicle budding at the Drosophila neuromuscular junction. EMBO J. 2002;21:1661-72.

[74] Kroll J, Jaime Tobon LM, Vogl C, Neef J, Kondratiuk I, Konig M, et al. Endophilin-A regulates presynaptic $\mathrm{Ca}(2+)$ influx and synaptic vesicle recycling in auditory hair cells. EMBO J. 2019;38.

[75] Sudhof TC. The synaptic vesicle cycle. Annu Rev Neurosci. 2004;27:509-47.

[76] Saheki Y, De Camilli P. Synaptic vesicle endocytosis. Cold Spring Harb Perspect Biol. 2012;4:a005645.

[77] Hadley D, Wu ZL, Kao C, Kini A, Mohamed-Hadley A, Thomas K, et al. The impact of the metabotropic glutamate receptor and other gene family interaction networks on autism. Nat Commun. 2014;5:4074.

[78] Cirrito JR, Kang JE, Lee J, Stewart FR, Verges DK, Silverio LM, et al. Endocytosis is required for synaptic activity-dependent release of amyloid-beta in vivo. Neuron. 2008;58:42-51.

[79] DeKosky ST, Scheff SW. Synapse loss in frontal cortex biopsies in Alzheimer's disease: correlation with cognitive severity. Ann Neurol. 1990;27:457-64. 
[80] Gomes LA, Hipp SA, Rijal Upadhaya A, Balakrishnan K, Ospitalieri S, Koper MJ, et al. Abetainduced acceleration of Alzheimer-related tau-pathology spreading and its association with prion protein. Acta Neuropathol. 2019;138:913-41.

[81] Spires-Jones TL, Attems J, Thal DR. Interactions of pathological proteins in neurodegenerative diseases. Acta Neuropathol. 2017;134:187-205.

[82] Whitehouse IJ, Jackson C, Turner AJ, Hooper NM. Prion protein is reduced in aging and in sporadic but not in familial Alzheimer's disease. J Alzheimers Dis. 2010;22:1023-31.

[83] Whitehouse IJ, Miners JS, Glennon EB, Kehoe PG, Love S, Kellett KA, et al. Prion protein is decreased in Alzheimer's brain and inversely correlates with BACE1 activity, amyloid-beta levels and Braak stage. PLoS One. 2013;8:e59554.

[84] Velayos JL, Irujo A, Cuadrado-Tejedor M, Paternain B, Moleres FJ, Ferrer V. The cellular prion protein and its role in Alzheimer disease. Prion. 2009;3:110-7.

[85] Campana V, Sarnataro D, Zurzolo C. The highways and byways of prion protein trafficking. Trends Cell Biol. 2005;15:102-11.

[86] Bridges LR, Andoh J, Lawrence AJ, Khoong CHL, Poon W, Esiri MM, et al. Blood-brain barrier dysfunction and cerebral small vessel disease (arteriolosclerosis) in brains of older people. J

Neuropathol Exp Neurol. 2014;73:1026-33.

[87] Thal DR, Capetillo-Zarate E, Del Tredici K, Braak H. The development of amyloid beta protein deposits in the aged brain. Sci Aging Knowledge Environ. 2006;2006:re1.

[88] Hurtado DE, Molina-Porcel L, Iba M, Aboagye AK, Paul SM, Trojanowski JQ, et al. A\{beta\} Accelerates the Spatiotemporal Progression of Tau Pathology and Augments Tau Amyloidosis in an Alzheimer Mouse Model. Am J Pathol. 2010;177:1977-88.

[89] Schwarz AJ, Yu P, Miller BB, Shcherbinin S, Dickson J, Navitsky M, et al. Regional profiles of the candidate tau PET ligand 18F-AV-1451 recapitulate key features of Braak histopathological stages. Brain. 2016;139:1539-50.

[90] Hanseeuw BJ, Betensky RA, Jacobs HIL, Schultz AP, Sepulcre J, Becker JA, et al. Association of Amyloid and Tau With Cognition in Preclinical Alzheimer Disease: A Longitudinal Study. JAMA Neurol. 2019.

[91] Hanseeuw BJ, Betensky RA, Mormino EC, Schultz AP, Sepulcre J, Becker JA, et al. PET staging of amyloidosis using striatum. Alzheimers Dement. 2018;14:1281-92.

[92] Braak H, Thal DR, Ghebremedhin E, Del Tredici K. Stages of the pathological process in Alzheimer's disease: Age categories 1 year to 100 years. J Neuropathol Exp Neurol. 2011;70:960-9. [93] Drummond E, Nayak S, Faustin A, Pires G, Hickman RA, Askenazi M, et al. Proteomic differences in amyloid plaques in rapidly progressive and sporadic Alzheimer's disease. Acta Neuropathol. 2017;133:933-54.

[94] Mandelkow EM, Stamer K, Vogel R, Thies E, Mandelkow E. Clogging of axons by tau, inhibition of axonal traffic and starvation of synapses. Neurobiol Aging. 2003;24:1079-85.

[95] Sultan A, Nesslany F, Violet M, Begard S, Loyens A, Talahari S, et al. Nuclear tau, a key player in neuronal DNA protection. J Biol Chem. 2011;286:4566-75.

[96] Tabaton M, Cammarata S, Mandybur T, Richey P, Kawai M, Perry G, et al. Senile plaques in cerebral amyloid angiopathy show accumulation of amyloid precursor protein without cytoskeletal abnormalities. Brain Res. 1992;593:299-303. 